\title{
Türk Çocuk Edebiyatında Tema: Kitap Katalogları Üzerine Bir İnceleme
}

\author{
Osman TURHAN*, Bayram BAŞ ${ }^{* *}$, Fatma KARACA TURHAN***
}

- Geliş Tarihi: 15.09.2020 • Kabul Tarihi: 13.10.2020 • Çevrimiçi Yayın Tarihi: 15.10.2020

\section{$\ddot{\mathbf{O} z}$}

$\mathrm{Bu}$ araştırmada Türk çocuk edebiyatında işlenen temaların tespit edilmesi amaçlanmıştır. $\mathrm{Bu}$ doğrultuda Türk çocuk edebiyatı, çocuk gelişimi ve çocuk eğitimi açısından incelenmiştir. Durum çalışması şeklinde tasarlanan bu araştırmada, ölçüt örneklem doğrultusunda dört yayınevinden altı yüz altmış beş Türk çocuk kitabı seçilmiştir. İnceleme, yayınevlerine ait kitap katalogları üzerinden yapılmıştır. Seçilen çocuk kitapları Türkçe dersi öğretim programındaki temalara göre nitel ve nicel içerik analizine tabi tutulmuştur. Bu doğrultuda çocuk kitaplarında on altı tema tespit edilmiştir. Çocuk kitaplarında genel temalar (erdemler, birey ve toplum vb.) daha çok, özel temalar (bilim ve teknoloji, sanat vb.) daha az işlenmektedir. Temalar çocuk gelişimi, çocuk eğitimi ve çeşitlik açısından değerlendirildiğinde bazı olumlu ve olumsuz sonuçlara ulaşılmaktadır. Çocuk kitaplarındaki bazı temalar, çocuk gelişimine katkı sağlayacak nitelikte değildir. Diğer temaların ise sosyal, zihinsel, duygusal, ahlaki gelişimi destekleme potansiyeli bulunmaktadır. Ancak gelişim alanları kapsamlı ve detaylı bir şekilde işlenmemiştir. Çocuk kitapları, öğretim açısından bazı sözel ders ve sözel yetkinlikler için uygun içeriğe sahiptir. Aynı durum diğer ders ve yetkinlikler için geçerli değildir. Ayrıca çocuk kitapları, informel açıdan çocuk eğitimini destekleyecek potansiyele sahiptir. Son olarak çocuk kitaplarında tematik açıdan pozitif ve kısmen sınırlı bir dünya sunulmuştur. Ancak sunulan bu tematik dünyanın çocukların ilgisini çekebileceği söylenebilir.

Anahtar sözcükler: Türk çocuk edebiyatı, kitap katalogları, tema, çocuk gelişimi, çocuk eğitimi.

\section{Atıf:}

Turhan, O., Baş, B. ve Karaca Turhan, F. (2021). Türk çocuk edebiyatında tema: Kitap katalogları üzerine bir inceleme. Pamukkale Üniversitesi Eğitim Fakültesi Dergisi, 52, 3158.doi:10.9779.pauefd.794327

\footnotetext{
* Arş. Gör., Yıldız Teknik Üniversitesi, osmant@yildiz.edu.tr, ORCID: 0000-0003-4800-5786

** Doç. Dr., Yıldız Teknik Üniversitesi, bbas@yildiz.edu.tr, ORCID: 0000-0003-3569-9395

*** Öğr. Gör., Yıldız Teknik Üniversitesi, fkaraca@yildiz.edu.tr, ORCID: 0000-0001-9665-1032
} 


\section{Giriș}

Tüm yazınsal unsurların (karakter, olay örgüsü, zaman ve mekân, üslup ve ton) birleşiminden meydana gelen tema, okuru merkeze almaktadır ve gerçek anlamını okurun zihninde kazanmaktadır (Horning, 1997). Bu nedenle diğer yazınsal unsurlardan daha derin bir anlama sahiptir ve çocukların zihninde daha kalıcıdır (Bucher ve Hinton, 2014, s. 33). Aynı zamanda çocukların tespit etmekte en çok zorlandığı yazın unsurudur (Barone, 2010, s. 113). Tema okur deneyimlerine dayandığı ve girift bir yapı sergilediği için tarif edilmesi zor bir kavramdır. Ancak en basit hâliyle yazarın hikâyeyi yazma nedeni veya bir hikâyenin ana fikri olarak tanımlanabilir (Tunnell ve Jacobs, 2007, s. 13). Yazarın okuyucuya aktardığı bu mesajın kelime veya kelime gruplarına (dostluk, yalnızlığın zorluğu vb.) indirgenmesi mümkündür. Ancak yazarın bu kavramları ne şekilde ele aldığını ortaya koyacak bir cümle, temayı daha iyi ifade etmektedir. Tema genellikle hikâyenin tamamına yayılmaktadır. Bazen hikâyedeki tek bir cümleye de sığdırılabilmektedir. Ayrıca ana temanın ardında kalan, belirsiz bir görünüme sahip, tespit etmesi daha zor olan ikincil temalar da bulunmaktadır (Anderson, 2006, s.38). Birbiriyle içe içe geçmiş ve birbirini besleyen örtük tema yapısı, bir hikâyenin-metnin inandırıcılığını ve edebî niteliğini arttırmaktadır (Sawyer, 2000, s. 74).

Çocuk kitapları, insanın bireysel ve sosyal durumunu ortaya koyan gerçek yaşamla ilişkili konulardan meydana gelmektedir (Wolf, 2004, s. 54). Bu nedenle çocukların birbirine benzeyen dünyalarına seslenmekte ve çocukluk tecrübelerinin benzerliğinden beslenmektedir (McClure, Garthwait ve Kristo, 2015, s. 14). Çocuklar da bu niteliklere sahip kitapları okumaya daha çok ilgi göstermektedir (Camp, 2007; Samuels, 1989). Bu doğrultuda kitaplarda çocukların hayatıyla doğrudan ilişkili olan konularda büyümenin getirdiği değişimler ve gereklilikler, aile ve arkadaşlar ile bireysel ilişkiler öne çıkmaktadır. Ancak gerçek hayata her zaman pozitif perspektiften bakılmamaktadır. Ölüm, hastalık, fakirlik, kötü alışkanlıklar, baskı, dışlanma, şiddet, gibi birey ve toplum kaynaklı problemlere de çocuk kitaplarında yer verilmektedir. (Bucher ve Hinton, 2014; Darigan, Tunnell ve Jacobs, 2002; Halverson, 2011). Ancak çocuk edebiyatında işlenen temalar bunlarla sınırlı değildir. Çocuğun bilişsel, ruhsal, sosyal gelişiminin üzerine kurulu olduğu; öğrenme, bireyselleşme, sosyalleşme, sağlık, spor, toplum, iletişim, bilim, teknoloji, okuma, zaman, mekân, kültür, hak, ahlak, erdem, duygu, doğa, sanat vb. her önemli kavram (Bee ve Boyd, 2009; Berger, 2000; Doğan, 2007; Gander ve Gardiner, 2004) çocuk edebiyatının tematik kapsamına girmektedir. Kitaplar bu temalar üzerinden çocukların hedef, arzu ve isteklerini belirlemesine, hayallerini canlı tutmasına, ufkunu genişletmesine, kendini 
O, Turhan, B, Baş ve F, Karaca Turhan/ Pamukkale Üniversitesi Eğitim Fakültesi Dergisi, 52, 31-58, 202133 tanımasına ve kişiliğini biçimlendirmesine, duygularını keşfetmesine ve duygularıyla yüzleşmesine, zihinsel becerilerini kullanmasına, aile ve arkadaşlarıyla daha kuvvetli ilişkiler kurmasına, sosyal becerilerini geliştirmesine, hayatın acı gerçeklerini -ölüm, ayrılık, mutsuzluk, ac1- anlamasına, insani değerleri fark etmesine, hayat tecrübesi edinmesine yardımc1 olmaktadır (Galda ve Cullinan, 2002; Nuba, Sheiman ve Searson, 2016).

Tüm çocuklar gelişimsel açıdan benzer karakteristik özelliklere sahiptir. Edebiyat yalnızca bu ortaklıktan faydalanarak dili, ırkı, kültürü farklı tüm çocukların hayatını yansıtabilmektedir (Galda ve Cullinan, 2002, s. 6). Örneğin ortaokul çocuklarının hayatları "arkadaş, aile, romantizm, cinsiyet, spor, hobi, yetenek, beceri, büyüme, olgunlaşma, heyecan, serüven, mizah, kariyer, bilim, teknoloji, hayvan, hayat problemleri, ahlak, değer, kültür, rol model ...” (Akbayır ve Şahin, 2005; Huck, Hepler ve Hickman, 1987) temelli temalarda kesişmektedir. Ancak bu durum, tüm çocukların benzer temaya sahip kitapları okumayı tercih ettiğini veya benzer okuma ilgilerine sahip olduğunu göstermemektedir. Çocukların okuma ilgilerinde cinsiyet, yaş ve gelişim düzeyleri açısından bazı benzerlikler olsa da her çocuğun kendine ait benzersiz estetik zevkleri vardır (Huck ve diğerleri, 1987). $\mathrm{Bu}$ nedenle çocuk kitaplarında tematik çeşitliliğin sağlanmasına dikkat edilmelidir (LynchBrown, Tomlinson ve Short, 2010, s. 42). Ayrıca tematik çeşitlilik sağlanarak çocukların ilgi alanlarına hitap etmenin yanı sıra yeni temalara da ilgi uyandırılmalıdır (Schanzer, 1996, s.74). Son olarak çocuğun gelişim sürecinin bir bütün olduğu ve bu süreci oluşturan parçaların birbiriyle ilintili olduğu unutulmamalıdır. Bu nedenle çocuğun fiziksel, zihinsel, duygusal, sosyal vb. gelişimiyle ilgili temaların yeterince işlenmesi gerekmektedir. İdeal olana yönelik bu beklenti, tek bir kitaptan ziyade çocuk kitaplarının kümülatif içeriğine yöneliktir.

Çocuk kitaplarında tematik açıdan asıl önemli olan çocukların kitaptan zevk almasıdır (Tomlinson ve Lynch-Brown, 2007, s. 27). Ancak çocuk edebiyatının edebi zevk ve estetik keyif vermek haricinde işlevleri de bulunmaktadır. Öncelikle okuma tüm alanlar için anahtar bir beceridir (Kim ve Anderson, 2011, s. 31). Buna göre çocuk kitaplarının özellikle yapılandırmacı yaklaşımı esas alan eğitim ortamlarında işlevsel olarak kullanılması mümkündür. Sosyal bilimler, fen bilimleri, sanat, beden eğitimi, sağlık gibi birçok farklı disiplinle ilgili derste çocuk kitaplarının sunduğu tematik imkânlardan yararlanılmaktadır (Davis ve Palmer, 1992; Pantaleo, 2002; Ross, 1994; Smith, 1991). Kurgusal olmayan çocuk kitapları, ders kitaplarının aksine herhangi bir ders konusu hakkında daha derinlemesine bilgi ve daha geniş perspektif sağlayabilmektedir (Darigan ve diğerleri, 2002, s. 507). 
Benzer bir durum kurgusal çocuk kitapları için de geçerlidir (Estes ve Vasquez-Levy, 2001, s. 510). Ek olarak kurgusal kitapların, kurgusal olmayanlara göre daha etkili, kalıcı ve işlevsel öğrenmelere kaynaklık ettiği gözlemlenebilmektedir (Appel ve Richter, 2007; Hopkins ve Weisberg, 2017).

Bağımlı (eğitsel amaçlı) okuma kadar bağımsız okuma da çocuklar için önemlidir (Baş, 2011, s. 179). Bu nedenle onların özgürce kitap seçmelerine izin verilmelidir. Çünkü çocuklar kendilerine seçim şansı verildiğinde gelişim düzeylerine uygun olan ve okumaktan zevk alacağı kitapları tercih etmektedir (Davila ve Patrick, 2010; Wilhelm, 2015). Kendi seçtikleri kitapları okuyan çocuklar kitap okumaya daha çok motive olmaktadır ve okuma becerilerini geliştirmektedir (Ivey ve Johnston, 2013; Krashen, 2005). Ancak çocuklar sıklıkla kendi seçtikleri değil, başkaları tarafından seçilen kitaplar üzerinden eğitim görmektedir (Morgan ve Wagner, 2013, s. 660). Ders kitapları üzerine yapılandırılmış Türk eğitim sisteminde de benzer bir durum geçerlidir. Fakat 2019 Türkçe Dersi Öğretim Programı'nda okul dışı/bağımsız okuma, metin dışı ve metinler arası okuma yoluyla teşvik edilmektedir (MEB, 2019, s. 8). Bu doğrultuda çocukların mümkün olduğu kadar çok kitaba ulaşmasına rehberlik edilmelidir (Krashen, 2006, s. 46). Çocuklar -özellikle ortaokul düzeyindeki- tema ve konu açısından kendi yaşlarına uygun, ilgilerini çekecek kitap bulmakta güçlük yaşayabilmektedir (Davila ve Patrick, 2010 s. 200). Kitap özeti, sınıf-yaş, tema-konu hakkında bilgi veren kitap tanıtım katalogları aracılığıyla tema ve konu açısından yaşa ve ilgiye uygun kitapların seçilmesi sağlanabilmektedir.

Özet olarak tema, bir kitabın niteliği ve içeriği hakkında önemli bir göstergedir. Çocuk edebiyatı tematik olarak çocukların kişisel gelişiminden destek almalı ve bu doğrultuda çocukların birbirinden farklılaşan edebî zevklerine yönelik tematik çeşitlilik sunmalıdır. Hem kurgusal hem de kurgusal olmayan çocuk edebiyatı, tematik yaklaşıma göre farklı derslerde kullanılabilecek öğretim materyali olma niteliğine sahiptir. Sunduğu akademik ve estetik fırsatlardan dolayı bağımsız okumaya önem verilmeli, çocukların tema ve konu açısından kendilerine uygun kitaplara ulaşmalarında çocuklara rehberlik edilmelidir. Söz konusu bilgiler, çocuk edebiyatının tematik açıdan incelenmesini önemli ve gerekli kılmaktadır. Buna göre araştırma kapsamında Türk çocuk edebiyatındaki temaların, rehber niteliği taşıyan kitap katalogları üzerinden incelenmesi amaçlanmıştır. Bu doğrultuda Türk çocuk edebiyatının çocuk gelişimini ve çocuk eğitimini nasıl destekleyebileceği irdelenmiştir. 


\section{Yöntem}

$\mathrm{Bu}$ araştırma durum çalışması niteliğindedir. Araştırma kapsamında bilgi kaynağı olan dokümanlar (çocuk kitabı yayın katalogları) incelenmiş, söz konusu dokümanlardan bilgiveri (tema/konu) toplanmış ve Türk çocuk edebiyatının tematik eğilimleri betimlenmiştir. Bu süreç durum araştırmasının özünü oluşturmaktadır (Creswell, 2016, s. 97). Tek bir analiz birimi (temalar), alt birimlere (alt temalar-konular) ayrılarak incelendiği için araştırma iç içe geçmiş tek durum çalışması şeklinde tasarlanmıştır (Yin, 2003, s. 42). Ancak Türk çocuk edebiyatındaki temalar ve konular hem eğitsel hem de eğitsel olmayan bir bağlamda yorumlanmış ve tartışılmıştır. $\mathrm{Bu}$ nedenle araştırmanın çok boyutlu bir yönü de bulunmaktadir.

\section{İnceleme Nesnesi}

Araştırmanın inceleme nesnesi amaçlı örneklem türlerinden ölçüt örnekleme göre seçilmiştir. Bu örneklemde, belirli ölçütlere uyan veri kaynakları araştırmaya dâhil edilmektedir (Patton, 2014, s. 243). Ölçüt örneklem doğrultusunda öncelikle kitap satış1 yapan internet siteleri incelenmiş, çocuk edebiyatı kategorisinde yer alan tüm yayınevleri tespit edilmiştir. Ardından yayınevlerinin internet sitelerinde yayın kataloglarının olup olmadığı analiz edilmiştir. Sonraki aşamada ulaşılan yayın katalogları betimsel analizine tabi tutulmuştur. Buna göre yayın kataloglarında "kitap özeti, sınıf-yaş, tema-konu, yazar" şeklinde kategorik bilgi veren yayınevleri seçilmiştir. Tema-konu, araştırmanın analiz birimi olduğu için; kitap özeti, temaların-konuların bağlamsal bir şekilde incelenebilmesi için; sınıf-yaş bilgisi, ortaokul düzeyine hitap eden çocuk kitaplarının seçilebilmesi için; yazar bilgisi, Türk yazarların çocuk kitaplarının seçilebilmesi için ölçüt olarak belirlenmiştir.

Ortaokul çocukları, son çocukluk ve erinlik dönemindedir. Bu geçiş dönemindeki çocukların somut ve soyut dünyası zenginleşmekte; zihinsel, ruhsal ve sosyal gelişimleri derinleşmektedir. Ayrıca farklı disiplinler, çocukların eğitim hayatlarında daha görünür ve etkili bir hale gelmektedir. Benzer şekilde bu dönemdeki çocukların edebiyat dünyası hem içerik (gelişim düzeyleri doğrultusunda) hem de tür (biyografi, dergi, roman, bilgilendirici metin vb.) açısından genişlemektedir. Bu nedenlerden dolayı ortaokul dönemindeki çocuk kitapları, tematik bir inceleme için ideal bir seçenektir. Ayrıca araştırmada "millî kültürümüz, millî mücadele ve Atatürk" temalarına yer verilmesi hem Türk çocuk edebiyatını hem de kültürel ve millî bilincin geliştiği ortaokul çağını ideal örneklem haline getirmektedir. 
İnceleme sonrasında ölçütleri karşılayan Türk çocuk kitapları $(\mathrm{f}=665)$ araştırmaya dâhil edilmiştir. Çocuk kitaplarının bazı kategorilere göre frekansları aşağıda sunulmuştur.

- Yayınevi: Can Çocuk (f=190), Tudem (f=190), Günışı̆̆ı Kitaplığı (f=154), Bilgi (f=131)

- Metin türü: roman ( $\mathrm{f}=411)$, öykü ( $\mathrm{f}=148)$, efsane-destan-masal ( $\mathrm{f}=28)$, bilgilendirici $(\mathrm{f}=27)$, şiir ( $\mathrm{f}=18)$, fikra-karikatür-bilmece-gülmece $(\mathrm{f}=12)$, anı-anlatı $(\mathrm{f}=7)$, biyografi $(\mathrm{f}=5)$, deneme-günlük-gezi-derleme-grafik roman $(\mathrm{f}=9)$

- Sınıf düzeyi: beşinci sınıf ( $\mathrm{f}=587$ ), altıncı sınıf ( $\mathrm{f}=446$ ), yedinci sınıf $(\mathrm{f}=248)$, sekizinci $\sin 1 f(f=182)$

- Yazar cinsiyetine göre: seksen sekiz kadın yazar ( $\mathrm{f}=352)$, doksan iki erkek yazar ( $\mathrm{f}=309)$

Yukarıdaki veriler incelendiğinde yayınevi ve yazar cinsiyetine göre çocuk kitaplarının homojen bir dağılım gösterdiği söylenebilir. Metin türüne ve sınıf düzeyine göre çocuk kitaplarının dağılımında ise dengesizlik bulunmaktadır. Bu dağılımlar yayınevlerinin yayın politikasını doğrudan yansıtmaktadır. Ek olarak yürütülen bu araştırmada kategoriler (yayınevi, metin türü, sınıf düzeyi, yazar cinsiyeti) arasında karşılaştırılma yapılmamıştır. $\mathrm{Bu}$ nedenlerle homojen örneklem seçimine gidilmemiştir.

\section{Veri Toplama Araci}

Araştırmada veri toplama aracı olarak dokümanlar kullanılmıştır. Dokümanların hangi kategorilere göre analiz edileceği, ilgili literatür doğrultusunda veri analizinden önce belirlenebilmektedir (Yıldırım ve Şimşek, 2013, s. 228). Verilerin analizinde kullanılacak kategorilerin araştırmanın amacını yansıtması, kapsamlı bir yapı sergilemesi ve her alt kategorinin diğerinden bağımsız olması gerekmektedir (Holsti, 1969, s. 95). Bu önermeye dayanarak kategorilerin oluşturulmasında, yayınevi kitap kataloglarında örnek alındığı için Türkçe Dersi Öğretim Programı esas alınmıştır. Söz konusu programda on altı tema ve bu temalara yönelik konu önerileri yer almaktadır (MEB, 2019, ss. 15-16).

\section{Verilerin Analizi}

İnceleme nesnesinden elde edilen veriler, veri toplama aracindaki on altı temaya ve bu temaların kapsamındaki konulara göre tümdengelimsel içerik analiziyle incelenmiştir. $\mathrm{Bu}$ teknikte, toplanan veriler önceden belirlenmiş kategorilere göre analiz edilmektedir (Patton, 2014, s. 453). Veri analizinde kullanılan birimler, kelime ve kelime gruplarıdır. Bu analiz birimleri biçimsel olarak sınırlı, anlamsal olarak kapsamlı bir yapıya sahiptir. Çünkü kelime 
O, Turhan, B, Baş ve F, Karaca Turhan/ Pamukkale Üniversitesi Eğitim Fakültesi Dergisi, 52, 31-58, 202137

ve kelime grupları, yayınevlerinin beyanları doğrultusunda konu ve tema olma özelliğine sahiptir. Bu durum, dokümanlardaki konuların ve temaların tespit edilmesinde önemli bir problem olan araştırma öznelliği ve yanlılığının (Bailey, 1994, s. 308) önemli düzeyde önüne geçmektedir.

Veri analizinde küçük birimden büyük birime doğru gidilmiştir. Bu birimler alt konu $<$ konu $<$ tema şeklinde sıralanmaktadır. Örneğin kitap kataloğundaki analiz etme konusu, analiz etme $<$ zihinsel gelişim $<$ kişisel gelişim şeklinde; kendini tanıma konusu, kendini tanıma $<$ kişisel gelişim şeklinde kodlanmıştır. Konunun kapsamına göre bu kavram zinciri uzamakta veya kısalmaktadır. Konuların doğru kodlanması özel kavram bilgisi gerektirdiğinden, öncelikle tematik referans kaynakları ve tematik sözlükler kullanılmıştır. Bu kaynakların yetersiz kaldığı durumlarda internet arama motorlarından faydalanılmıştır.

Kitap kataloglarında Bilgi ve Tudem yayınevleri yalnızca alt tema-konu, Günışığ1 Kitaplığı ve Can Çocuk yayınevi hem tema hem alt tema-konu bilgisini paylaşmaktadır. Ancak kataloglarda ayrı bölümlerde yer aldıkları için hangi konuların hangi temalarla bağlantılı olduğu açık değildir. Bazen dokümandaki verinin (kelime, kelime grubu vb.) içinde bulunduğu bağlam incelemenden hangi kategoride ele alınacağına karar vermek oldukça zordur veya imkânsızdır. Böyle bir durumda araştırmacıların, verileri kodlarken bağlama dikkat etmesi gerekmektedir (Bailey 1994, s. 308). Bu noktada araştırmacılar, bir kitapla ilgili kataloglarda verilen tüm bilgileri (özet, etkinlik, tanıtım yazısı, tema, konu) ilişkisel olarak dikkatle incelemiştir. $\mathrm{Bu}$ inceleme doğrultusunda alt $\mathrm{konu}<\mathrm{konu}<$ tema şeklinde tematik kodlama gerçekleştirilmiştir. Örneğin bir çocuk kitabının konuları arasında "İstanbul” konusu bulunmaktadır. Bu konu öncelikle "zaman ve mekân” teması kapsamına girmektedir. Çocuk kitabında kültür odaklı bir tema varsa veya kitap özetinde İstanbul'un tarihi ve kültürel değerine değinilmişse, bu konu aynı zamanda "millî kültürümüz” temasına alınmıştır. Farklı bir örnek olarak "hayat" konusu, yalın hâliyle hiçbir tema kapsamına girmemektedir. Hayatla ilgili hem temada hem de kitap özetinde ek bilgiye ulaşılamamışsa, bu konu araştırmadan çıkartılmıştır.

Verilerin kodlanması iki araştırmacı tarafından ayrı bir şekilde yapılmıştır. Tüm veriler kodlandıktan sonra araştırmacılar arasındaki kodlama uyumu [Güvenirlik = Görüş Birliği / (Görüş Birliği + Görüş Ayrılığı)] hesaplanmıştır (Miles ve Huberman, 1994). Bu doğrultuda görüş birliğinin \%85 olduğu tespit edilmiştir. Bu değer araştırmacıların birbiriyle tutarlı bir analiz süreci yürüttüğünü göstermektedir. Sonraki süreçte araştırmacılar, uyumsuz kodlanan konuları birlikte incelemiş ve tekrar kodlama yapmıştır. Tekrar kodlama süreci 
tamamlandıktan sonra dış denetimin sağlanabilmesi için çocuk edebiyatı alanında uzman olan bir araştırmacıdan görüş alınmıştır. Bu araştırmacıya çalışmanın bağlamı ve veri analiz süreci açıklanmış, kendisiyle 70 çocuk kitabının verileri paylaşılmıştır. Lombard, Snyder-Duch ve Bracken'e (2002) göre örneklemin en az \%10'unun paylaşılması yeterlidir. Araştırmacının kodlamaları doğrultusunda kod uyumu \%81 olarak hesaplanmış ve bu yüzde yeterli görülmüş̧ür.

Tümdengelimsel nitel veri analizi tamamlandıktan sonra veriler, iki farklı kategoride (tema, konu) nicel içerik analizine (frekans/sıklık) tabi tutulmuştur. Bu doğrultuda çocuk kitaplarının hangi temalar, temaların hangi konuların çevresinde işlendiği tespit edilmiştir. Böylece Türk çocuk kitaplarındaki tematik eğilimler ortaya çıkarılmıştır.

\section{Verilerin Sunumu}

Dokümanlar içerik analizine tabi tutulduktan sonra dört farklı nicel yaklaşımla sunulabilmektedir: (1) tema ve konunun varlığı veya yokluğu; (2) tema ve konunun frekansısıklığı; (3) tema ve konunun yüzde dağılımı; (4) tema ve konunun kapsadığı alan (Bailey, 1994, s. 309). Ancak doküman analiziyle elde edilen verilerin nicelleştirilerek veya sayısallaştırılarak sunulması zorunlu değildir. Araştırmacı, söz konusu verileri düzyazı şeklinde raporlaştırma inisiyatifine sahiptir (Yıldırım ve Şimşek, 2013, s. 200). Bu araştırmada veriler hem nitel ve hem de nicel yaklaşımla sunulmuştur. Ancak nitel paradigmanın ve tematik çalışmanın doğasına uygun olarak, araştırma verileri nicel göndermelerle (var-yok, az-çok, öne çıkan-arkada kalan, odaklanılmış-göz ardı edilmiş vb.) birlikte mümkün olduğunca nitel bir şekilde sunulmaya çalışılmıştır.

\section{Geçerlik ve Güvenirlik}

Geçerli ve güvenilir bir nitel araştırmanın inanılabilir, aktarılabilir, sağlam ve onaylanabilir olması gerekmektedir (Lincoln ve Guba, 2013, ss. 104-105). Bu gereklilik doğrultusunda araştırma kapsamında bazı stratejilere başvurulmuştur (Merriam ve Tisdell, 2015, s. 259). Buna göre geçerli ve güvenilir bir araştırma için amaçlı örneklem seçimi yapılmış, veri kaynağı ve araştırmacı üçgenlemesine gidilmiş, araştırmanın bağlamı betimlenmiş, araştırmanın yürütülme süreci ve bulgular detaylı bir şekilde açıklanmış, bağımsız araştırmacı denetlemesine başvurulmuş, araştırmacı öznelliğine ve yanlılığına yönelik tedbirler alınmıştır. 


\section{Bulgular}

Türk çocuk kitaplarında tespit edilen temaların frekansa (f) ve yüzdeye (\%) dayalı istatistikleri Tablo 1'de verilmiştir.

Tablo 1. Temaların Tespit Edildiği Kitap Sayısı

\begin{tabular}{lccccc}
\hline & $\mathrm{f}$ & $\%$ & & $\mathrm{f}$ & $\%$ \\
\hline Erdemler & 505 & 76 & Vatandaşlık & 218 & 33 \\
Birey ve Toplum & 495 & 74 & Millî Kültürümüz & 173 & 26 \\
Kişisel Gelişim & 469 & 71 & Sanat & 148 & 22 \\
İletişim & 440 & 66 & Sağlık ve Spor & 105 & 16 \\
Duygular & 408 & 61 & Hak ve Özgürlükler & 103 & 15 \\
Çocuk Dünyası & 404 & 61 & Bilim ve Teknoloji & 98 & 15 \\
Zaman ve Mekân & 333 & 50 & Okuma Kültürü & 68 & 10 \\
Doğa ve Evren & 275 & 41 & Millî Mücadele ve Atatürk & 18 & 3 \\
\hline
\end{tabular}

Türk çocuk kitaplarında en çok Erdemler teması bulunmaktadır. Birey ve Toplum, Kişisel Gelişim, İletişim, Duygular, Çocuk Dünyası temaları da çok sayıda çocuk kitabında mevcuttur. Bu temaları sırasıyla Zaman ve Mekân, Doğa ve Evren temaları takip etmektedir. Vatandaşlık, Millî Kültürümüz, Sanat, Sağlık ve Spor, Hak ve Özgürlükler, Bilim ve Teknoloji, Okuma Kültürü, Millî Mücadele ve Atatürk temaları ise çocuk kitaplarında az veya çok az yer almaktadır.

\section{Erdemler}

Erdemler temasının içeriği şu şekilde sıralanmaktadır: arkadaşlık $(\% 22,4)$, sevgi $(\% 18,5)$, dayanışma (\%15,0), empati (\%5,4), sorumluluk (\%3,8), iyilik (\%3,4), saygı (\%3,0), önyargı $(\% 2,8)$, adil olma $(\% 2,8)$, erdem $(\% 2,7)$, cesaret $(\% 2,6)$, yardımlaşma $(\% 2,2)$, etik $(\% 2,1)$, dürüstlük (\%1,9), barlş (\%1,9), hoşgörü (\%1,5), fedakarlık (\%1,3), kardeşlik $(\% 0,9)$, koruma (\%0,9), güven $(\% 0,6)$, paylaşma $(\% 0,6)$, doğruluk $(\% 0,6)$, azim-çalışkanlık $(\% 0,5)$, vicdanl olmak (\%0,5), merhamet (\%0,4), değerbilme (\%0,3), vefa (\%0,2), uzlaşma-anlaşma (\%0,2), bilgelik (\%0,2), bağlllık (\%0,2), cömertlik (\%0,1), iyilikseverlik (\%0,1), sadakat $(\% 0,1)$, bencillik $(\% 0,1)$, irade $(\% 0,1)$, duyarlılık $(\% 0,1)$, bağışlama $(\% 0,1)$.

Temaya karakter erdemleri temelinde duyguların ve etkilenimlerin hâkim olduğu görülmektedir. Düşünce erdemleri ise oldukça düşük düzeyde işlenmiştir. Başka bir ifadeyle 
temada ahlaki erdemlere odaklanıldığı, fikir erdemlerinin ise göz ardı edildiği söylenebilir. Karakter erdemlerinde, çocuğun sosyal hayatında kişiler arası iletişimini ve ilişkilerini güçlendirecek erdemlerin baskınlığı gözlemlenmektedir. Aynı zamanda karşıdaki insanıncanlının merkeze alındığı, yardım ve paylaşma merkezli erdemler de bulunmaktadır. Ayrıca kişisel gelişimi destekleyen erdemler de işlenmektedir. Son olarak ortaokul düzeyindeki çocukların sosyal gelişiminde önemli bir soyut kavram olan iyilik ve kötülüğün çocuk kitaplarındaki varlığı dikkat çekicidir.

Tema eğitsel açıdan önemli kabul edilen kök değerlere (adalet, arkadaşlık, dürüstlük, öz denetim, sabır, saygı, sevgi, sorumluluk, yardımseverlik) göre incelendiğinde, temada en çok işlenen iki konunun (arkadaşlık, sevgi) kök değer olduğu görülmektedir. Ayrıca sorumluluk, saygı, adalet, yardımlaşma ve dürüstlük konuları da temada ön plandadır. Ancak sabır ve öz denetim değerlerine temada yer verilmemiştir. Temaya kök değerlerden arkadaşlığı, dürüstlüğü, sabrı, saygıyı, sevgiyi, yardımseverliği destekleyen değerlerinerdemlerin varlığı da eklendiğinde, temanın eğitsel açıdan önemli bir potansiyel barındırdığı anlaşılmaktadır.

Erdemler, çocuğun ahlaki gelişimiyle yakından ilişkilidir. Ahlaki gelişimlerinin ilk dönemlerinde olan ortaokul düzeyindeki çocuklar, erdemleri somutlaştırıldığı zaman daha iyi algılamakta ve anlamaktadır. Çocuk kitapları gerçek kişileri, olayları, ilişkileri yansıtması nedeniyle ahlaki olarak ideal veya tartışmalı olan durumları aktarmak, diğer bir ifadeyle erdemleri somutlaştırmak için uygun bir araçtır. Bu doğrultuda temanın çocukların ahlaki gelişimini destekleme potansiyeli bulunmaktadır. Ancak temada bazı karakter erdemleri üzerine yoğunlaşılması, bu potansiyeli sınırlamaktadır.

\section{Birey ve Toplum}

Birey ve Toplum temasının içeriği şu şekilde sıralanmaktadır: dayanışma (\%21,2), birey ve toplum $(\% 9,4)$, toplumsal hayat ve ilişkiler $(\% 8,3)$, empati $(\% 7,9)$, meslekler $(\% 7,7)$, bireysel farklılıklar (\%7,0), medeniyet (\%6,2), komşuluk ilişkileri $(\% 5,0)$, adalet $(\% 4,0)$, barlş (\%3,3), kırsal kültür (\%3,3), kent kültürü $(\% 2,6)$, gurbet (\%2,5), toplumsal kurallaryasalar (\%1,9), eşitlik (\%1,8), kardeşlik (\%1,2), kültürel farklllıklar $(\% 1,1)$, çok kültürlülük $(\% 0,8)$, dezavantajli gruplar $(\% 0,8)$, iktidar $(\% 0,8)$, sosyal hizmet ve sorumluluk $(\% 0,8)$, sosyo-ekonomik farklılıklar (\%0,6), hukuk (\%0,3), misafirperverlik (\%0,3), toplumsal bask $(\% 0,3)$, popüler kültür $(\% 0,3)$, çok dillilik (\%0,1), farklılıklara saygl $(\% 0,1)$, hayat becerileri $(\% 0,1)$, sosyokültürel farkındalık $(\% 0,1)$. 
O, Turhan, B, Baş ve F, Karaca Turhan/ Pamukkale Üniversitesi Eğitim Fakültesi Dergisi, 52, 31-58, 202141

Birey ve Toplum temasında yalnızca tema adının verildiği, tema kapsamında herhangi bir konunun yer almadığı önemli sayıda çocuk kitabı bulunmaktadır. Birey ve Toplum temasındaki konuları; erdemler ve değerler, farklılık ve farkındalık, olumsuz toplumsal gerçekler, vatandaşlık, haklar, iletişim, ekonomi, kültür, mekân ve yerleşim şeklinde sınıflandırmak mümkündür. Konular kümülatif olarak incelendiğinde, temanın evrensel ve kültürlerarası değil kültürel bir bağlamda ele alındığı görülmektedir. Temadaki konularda, ahlak-erdem, sosyoloji ve iletişim temelli konuların ağırlığı hissedilmektedir. Aynı zamanda ekonomi, coğrafya, siyaset-politika, insan hakları, hukuk şeklinde örneklendirebilecek alanlar temayı desteklemektedir.

Çocuk edebiyatı, yapısı gereği toplumu ve bireyin toplumla ilişkisini yansıtma niteliğine sahiptir. Fakat Birey ve Toplum, teorik olarak farklı disiplinleri içinde barındıran geniş bir kapsamlı bir temadır. Bu nedenle çocuk edebiyatında, söz konusu temayla ilgili kavramsal ve alansal çeşitliliğin sağlanması gerekmektedir. İncelenen çocuk kitapları bu çeşitlilikten kısmen yoksundur. Ayrıca tema çoğunlukla erdemler, vatandaşlık, zaman ve mekân, iletişim gibi temalarda da işlenen konulardan meydana gelmektedir. Kültürel, sosyal, politik ve ekonomik bağlamda ancak bu tema kapsamında işlenmesi mümkün olan birçok konu temada göz ardı edilmiştir. Ancak tema, bahsedilen sınırlılıklar dâhilinde, çocukların birey ve toplum dinamiklerini sezmesini ve bu bağlamdaki kavramları öğrenmesini sağlayacak potansiyele sahiptir.

\section{Kişisel Gelişim}

Kişisel Gelişim temasının içeriği şu şekilde sıralanmaktadır: zihinsel gelişim $(\% 17,8)$, hayal kurmak (\%16,9), mücadele (\%6,9), empati (\%6,8), yaratıcllı (\%6,7), kendini tanıma (\%6,3), olgunlaşma $(\% 5,5)$, sanatsal gelişim $(\% 5,1)$, sorumluluk $(\% 4,9)$, eğitim-öğrenme (\%3,8), gözlem (\%2,3), duygusal gelişim (\%2,3), meslek seçimi (\%1,9), sosyal gelişim $(\% 1,8)$, kişisel gelişim $(\% 1,8)$, öz güven $(\% 1,4)$, karar verme $(\% 0,8)$, kendini ifade etme $(\% 0,8)$, başarı (\%0,7), özveri gösterme (\%0,7), arayış $(\% 0,6)$, çalışkanlık $(\% 0,5)$, öz saygı $(\% 0,5)$, yetenek $(\% 0,5)$, olumlu düşünme $(\% 0,4)$, rekabet etme $(\% 0,4)$, yönetme-liderlik etme $(\% 0,4)$, kararlı olma $(\% 0,4)$, kişilik tipleri $(\% 0,2)$, hobi ve kurs $(\% 0,2)$, beceri $(\% 0,1)$, öz eleştiri $(\% 0,1)$, seçim yapma $(\% 0,1)$, uyum sağlama $(\% 0,1)$, rehberlik alma $(\% 0,1)$.

Kişisel Gelişim temasında çeşitli gelişim türleri yer almaktadır. Tekil olarak en çok zihinsel gelişime odaklanılmaktadır. Ardından sırasıyla sanatsal gelişim, duygusal gelişim ve sosyal gelişim gelmektedir. Temada yer alan tüm konular kümülatif olarak 
değerlendirildiğinde zihinsel, sanatsal, duygusal ve sosyal gelişimi destekleyen birçok konunun temada yer aldığ 1 görülmektedir. Ayrıca Kişisel Gelişim temasındaki konular daha farklı şekillerde de gruplanabilmektedir. Bu doğrultuda söz konusu temada yaratıcılık, akademik ve mesleki gelişim, erdemler ve değerler, seçim ve karar, iletişim ve insan ilişkileri, yetenek ve beceri, üst biliş ve özyönetim temelli konular bulunmaktadır. Özel konu alanlarından kariyer ve edebiyata temada ağırlık verilirken diğer özel konu alanlarına (sağlık, spor, müzik, teknoloji vb.) yer verilmediğini de eklemek gerekmektedir.

Konular kümülatif olarak incelendiğinde çocuk kitaplarında, çocukların gelişim alanlarına çeşitlilik açısından bütüncül bir şekilde yaklaşıldığı söylenebilir. Bu gelişim alanlarını zihinsel gelişim, benlik-kimlik gelişimi, sanatsal gelişim, duygusal gelişim, sosyal gelişim, mesleki gelişim olarak sıralamak mümkündür. Temada ahlak gelişimi, cinsel gelişim ve kısmen dil gelişimi göz ardı edilmiştir. Kişisel gelişime çok boyutlu bir bakış sergilenmesi nedeniyle, tema önemli bir potansiyele sahiptir. Ancak temada bazı konular ve kişisel gelişim türleri üzerine yoğunlaşılması, bu potansiyeli sınırlamaktadır.

\section{İletişim}

İletişim temasının içeriği şu şekilde sıralanmaktadır: aile (\%35,6), arkadaşlık (\%33,0), iletişim (\%10,0), komşuluk ilişkileri (\%5,2), nesillerarası iletişim $(\% 4,1)$, diğer canlılarla iletişim (\%3,6), kitle iletişim araçlart-iletişim araçları (\%2,3), insanlarla iletişim (\%2,0), kendini ifade etme $(\% 1,4)$, ögrenci öğretmen iletişimi $(\% 0,7)$, iletişim becerileri $(\% 0,6)$, kültürler arası iletişim (\%0,6), yazılı iletişim (\%0,4), kültürel iletişim $(\% 0,3)$, etkili iletişim $(\% 0,1)$.

İletişim temasında yalnızca tema adının verildiği, tema kapsamında herhangi bir konunun yer almadığı önemli sayıda çocuk kitabı bulunmaktadır. Temada yer alan konularda sözsüz ve yazılı iletişimden ziyade sözlü iletişimin ağırlığı sezilmektedir. Temaya bireyler arası iletişim hakimdir. Bu bireyler ise çocuğun yakın çevresindeki kişilerden oluşmaktadır. Konular tekil olarak ele alındığında arkadaşların ve ailenin temanın tamamına hâkim olduğu görülmektedir. Ayrıca kültür iletişimine, iletişim becerilerine, iletişim araçlarına, diğer canlılarla iletişime yer verilmektedir. Ancak bu konular, önemli bir ağırlığa sahip değildir.

Bağlamları açısından incelendiğinde iletişimin çoğunlukla sosyal, kısmen kültürel bağlamda işlendiği görülmektedir. Temada iletişim, zaman (anında veya sonradan dönüt vb.) ve mekân (resmi veya samimi ortam vb.) unsurlarına sahip değildir. Çocukların konuşma 
O, Turhan, B, Baş ve F, Karaca Turhan/ Pamukkale Üniversitesi Eğitim Fakültesi Dergisi, 52, 31-58, 202143 becerilerinin gelişimiyle zihinsel, duygusal ve sosyal açıdan bağlantılı olan iletişim becerilerine, kaygılarına ve engellerine temada yeterince değinilmemiştir. Benzer şekilde iletişim araçlarına (telefon, bilgisayar vb.) oldukça az yer verilmiştir. Söz konusu araçlar çocukların iletişim kültüründe önemli bir rol oynadığı için bahsedilen eksiklik daha fazla göze çarpmaktadır. Ayrıca iletişim araçlarıyla bağlantısı olan iletişim türlerinin (görsel iletişim, bilgi iletişimi, basılı, elektronik iletişim vb.) temadaki eksikliği de dikkat çekmektedir.

İletişim teması, ağırlıklı olarak çocukların sosyal gelişimleri üzerine temellendirilmiştir. Ortaokul dönemindeki çocuklar öncelikle ailesi ve arkadaşlarıyla, daha sonra öğretmenleri ve diğer yakın çevresiyle iletişim halindedir. Bu kişilerle (özellikle aile ve arkadaşlar) kurulan iletişimin niteliği, çocukların geliştireceği sosyal kimliğin kuvvetli bir göstergesidir. Bu nedenle tema, çocukların sosyal gelişimi açısından önemli bir potansiyel kazanmaktadır. Ancak bahsedilen eksiklikler, bu potansiyeli sınırlamaktadır.

\section{Duygular}

Duygular temasının içeriği şu şekilde sıralanmaktadır: sevgi $(\% 31,2)$, duygular $(\% 12,6)$, merak $(\% 10,4)$, empati $(\% 9,1)$, umut $(\% 6,7)$, saygl $(\% 5,1)$, cesaret $(\% 4,4)$, özlem $(\% 2,9)$, aşk (\%2,9), korku (\%2,1), yalnızlık (\%2,1), kaygl-stres (\%1,6), mutluluk (\%1,6), kıskançlık $(\% 1,3)$, heyecan $(\% 1,0)$, üzüntü $(\% 0,8)$, güven $(\% 0,8)$, tutku $(\% 0,8)$, veda $(\% 0,5)$, kibir $(\% 0,3)$, stres $(\% 0,3)$, özenme $(\% 0,3)$, vefa $(\% 0,3)$, bağışlama $(\% 0,2)$, pişmanlık $(\% 0,2)$, çaresizlik $(\% 0,2)$, sıkıntı $(\% 0,2)$.

Duygular temasında yalnızca tema adının verildiği, tema kapsamında herhangi bir konunun yer almadığı önemli sayıda çocuk kitabı bulunmaktadır. Temada hem pozitifolumlu duyguların hem de negatif-olumsuz duyguların çeşitliliği dikkat çekicidir. Ancak pozitif-olumlu duygular çok daha baskındır. Temadaki konuları aşk/sevgi, keyif/neşe, hüzün/keder, korku ve öfke şeklinde sınıflandırmak mümkündür. Bu kategoriler arasında öncelikle aşk/sevgi, ardından keyif/neşe öne çıkmaktadır. Hüzün/keder, korku ve öfke daha arka planda kalmaktadir.

Sevgi, keyif ve neşe temelli duygular, ortaokul düzeyindeki çocukların kişilik gelişiminde etkili olan ortak duygulardır. Bu nedenle çocuk kitaplarında yüksek düzeyde yer alması olumlu bir durumdur. Erinlik dönemindeki (ortaokul son dönem) çocuklar, önceki çocukluk dönemine göre tüm duyguları daha yoğun ve düzensiz bir şekilde yaşamaktadır. Özellikle bu dönemdeki çocuklarda aşk, hüzün/keder, korku, öfke temelli duygular etkisini 
iyice hissettirmektedir. Söz konusu duygular çocuk kitaplarında temsil edilmektedir. Ancak bu duyguların temsil düzeyi diğer duygulardan çok daha düşüktür. Empati, ortaokul çocuklarının duygusal gelişiminde etkili bir duygudur. Çocuk kitaplarında bu duygunun yüksek düzeyde sunulması dikkate değerdir.

Tema çocukların kendi duygularını tecrübe etmesini sağlayacak ve onların duygusal gelişimini destekleyecek potansiyele sahiptir. Ancak farklı niteliklere sahip duyguların yeterince temsil edilmemesi ve bazı duygulara odaklanılması bu potansiyeli sınırlamaktadır.

\section{Çocuk Dünyası}

Çocuk Dünyası temasının içeriği şu şekilde sıralanmaktadır: hayal (\%22,2), macera (\%11,0), okul (\%10,0), merak (\%9,1), gizem (\%7,5), büyümek (\%6,6), olağanüstülük (\%5,7), mizah (\%5,3), yolculuk (\%3,8), oyun (\%3,5), baskı ve dışlanma (\%2,5), tatil (\%2,5), ebeveyn ayrllı̆̆l-kaybı (\%2,3), sinav-ödev (\%1,6), çocuk dünyası (\%1,2), rüya $(\% 0,9)$, çocuk kültürü $(\% 0,7)$, ĕglence $(\% 0,7)$, keşif $(\% 0,7)$, kahramanlık $(\% 0,6)$, alışkanlıklar $(\% 0,4)$, hayranlı-özenme (\%0,3), özel günler $(\% 0,3)$, dijital oyunlar $(\% 0,1)$, hediye $(\% 0,1)$, gezi $(\% 0,1)$.

Çocuk Dünyası temasında çocukların zihinsel, duygusal ve sosyal gelişiminde önemli rolü olan çeşitli anahtar kavramlar yer almaktadır. Bu konular, çocuk kitaplarında oldukça baskındır. Tema, pozitif bir yaklaşımla ele alınmıştır. Ancak bazı olumsuz ve negatif durumlara da yer verilmektedir. Ayrıca tema, metin türlerinin yoğun etkisi altındadır.

Dinamik bir niteliğe sahip olan temada, eğlenme ve keşfetme üzerine yoğunlaşılmaktadır. Temadaki soyut kavramlar, çocukların düşsel-duygusal dünyasını zenginleştirecek niteliktedir. Temada çocukların fiziksel hayatına fazla yer verilmemiştir. Çocukların günlük hayatı, eğitim ve öğretim üzerine temellendirilmiştir. Ayrıca oyun, yolculuk, tatil gibi çocukların keyif alacağı etkinliklere de kısmen yer verilmiştir. Teknolojik gelişmeler ve bu gelişmelerin getirdiği değişimler günümüzde çocuk kültürünü şekillendirecek ve değiştirecek ölçüde etkili olmasına rağmen, bu durum temaya yansımamıştır. Çocukların dünyasında kısa zaman diliminde meydana gelen değişiklikler, büyüme konusunda açı̆̆a çıkmaktadır. Ancak temada, ortaokul son dönemden ziyade ilk döneme odaklanılmıştır. Erinlik çağında olan çocukların fizyolojik, psikolojik ve sosyal dünyalarını yansıtan kavramlar temada göz ardı edilmiştir.

Çocuklar yaşadıkları hayatın ve kendi dünyalarının karşılığını buldukları takdirde bir kitabı okumaya başlamakta veya okumaya devam etmektedir. Hem dönemsel (son çocukluk- 
O, Turhan, B, Baş ve F, Karaca Turhan/ Pamukkale Üniversitesi Eğitim Fakültesi Dergisi, 52, 31-58, 202145 erinlik) hem de bireysel (mizaç, deneyim, sosyoekonomik durum vb.) farklılıklardan dolayı ortaokul çocuklarının dünyaları birbirinden farklılaşmaktadır. Bu farklılığın çeşitlilik olarak kitaplara yansıtılması, çocukların kitap okumaya yönelik ilgi ve isteklerini olumlu yönde etkileyecektir. Bu bağlamda temanın bir noktaya kadar yeterli olduğu söylenebilir.

\section{Zaman ve Mekân}

Zaman ve Mekân temasının içeriği şu şekilde sıralanmaktadır: geçmiş şimdi gelecek (\%24,6), çevremiz (\%14,5), okulumuz $(\% 13,7)$, şehirler $(\% 11,3)$, zaman ve mekân $(\% 7,5)$, ülkeler (\%5,6), kırsal yerleşim (\%5,0), tatil ve turizm (\%3,8), bölgeler-coğrafya $(\% 3,4)$, evimiz (\%2,0), kamp (\%1,0), sosyal kurumlar (\%1,0), tarihî mekânlar (\%0,8), kütüphane $(\% 0,8)$, mahalle $(\% 0,6)$, hayvanat bahçesi $(\% 0,6)$, apartman $(\% 0,4)$, müze $(\% 0,4)$, özel günler (\%0,4), gezginler (\%0,2), sinıfimız (\%0,2), otel (\%0,2), ticarethane (\%0,2), bakımevi $(\% 0,2)$, park $(\% 0,2)$, aşevi $(\% 0,2)$, itfaiye $(\% 0,2)$, belediye $(\% 0,2)$, sirk-lunapark-panayır $(\% 0,2)$, pazaryeri $(\% 0,2)$, zaman $(\% 0,2)$, tarih $(\% 0,2)$, anı $(\% 0,2)$.

Zaman ve Mekân temasında yalnızca tema adının verildiği, tema kapsamında herhangi bir konunun yer almadığı önemli sayıda çocuk kitabı bulunmaktadır. Temada tekil olarak en çok işlenen konu zamanla ilgili olmasına rağmen, kümülat if olarak mekânla ilgili konular odak noktayı oluşturmaktadır. Zamanla ilgili konularda net bir ayrıma gidilmemiş; geçmiş, şimdi ve gelecek alt dilimlere ayrılmamıştır. Ayrıca zaman; fizik, astronomi, tarih, arkeoloji, jeoloji gibi bilim alanlarıyla ilişkilendirilmemiştir. Çocukların ilgisini çekebilecek zaman algısı, zamanda yolculuk, mitoloji, bilim kurgu gibi alt konulardan da faydalanılmamıştır. Son olarak aynı temada olmalarına rağmen zaman ve mekân birbirinden bağımsız kalmıştır.

Mekânla ilgili konuları küçük ölçekli ve büyük ölçekli şeklinde sınıflandırmak mümkündür. Odak noktayı küçük ölçekli mekânlar oluştursa da büyük ölçekli mekânlar da önemli derecede işlenmektedir. Büyük ölçekli mekânlar Türkiye çatısında kültürel bir sınırlılığa sahiptir. Küçük ölçekli mekânlar çocuğun yakın çevresi üzerine temellendirilmiştir. Temada kültürel, eğitsel ve özellikle eğlence amaçlı ziyaret edilebilen mekânların da işlendiği görülmektedir. Ayrıca resmî ve sosyal kurumlara da yer verilmektedir. Temadaki mekânların bugünün bilindik ve gerçek mekânlarından oluşması hem olumlu hem de olumsuz bir şekilde yorumlanabilir. Söz konusu mekânlar çocukların günlük hayatıyla doğrudan ilişki olduğu için çocuğun gerçekle kurguyu daha iyi ilişkilendirmesini ve okumaya daha motive olmasını sağlayabilmektedir. Ancak çocuğun 
hayal dünyasının zenginleşmesinde ve hayal gücünün gelişmesinde bilinmeyen veya az bilinen mekânlar (olağanüstü, geçmiş veya gelecek zamanda bulunan, yakın çevresinde bulunmayan vb.) daha etkilidir.

\section{Doğa ve Evren}

Doğa ve evren temasının içeriği şu şekilde siralanmaktadır: hayvanlar (\%16,0), çevre $(\% 15,1)$, canlılar $(\% 14,7)$, doğa $(\% 14,2)$, çevrenin korunması $(\% 8,6)$, zaman bilinci $(\% 6,5)$, kırsal yerleşim (\%4,5), doğal yaşam (\%4,3), doğa ve evren (\%2,5), mevsimler (\%2,2), doğa olaylarl (\%2,0), yeryüzü (\%1,6), su (\%1,4), bitkiler $(\% 1,1)$, doğal afetler $(\% 1,1)$, dünya $(\% 0,9)$, uzay $(\% 0,9)$, atmosfer $(\% 0,9)$, toprak işleri-tartm $(\% 0,7)$, gezegenler $(\% 0,4)$, manzaralar (\%0,2), yıldızlar (\%0,2), çevre kirliliği $(\% 0,2)$.

Doğa ve Evren temasında evrene yönelik konular hem çeşitlilik hem de sıklık açısından göz ardı edilmiş, doğaya yönelik konulara odaklanılmıştır. Söz konusu yetersizlikten dolayı evren alt temasına yönelik eğilimler tespit edilememektedir. Ancak temada doğanın ağırlıklı olarak yaşam ve canlılık perspektifinden ele alındığı söylenebilir. Dünyada süregelen iklimsel ve çevresel değişimlere ve tehlikelere işaret etmesi açısından önemli olan çevre bilinci, çocuk kitaplarında kayda değer düzeyde işlenmektedir. Doğanın ana unsurlarını ve süreçlerini oluşturan toprak, su, hava ile ilgili konulara da temada yer verildiği görülmektedir. Temada zaman bağlamında yalnızca zaman bilinci işlenmektedir. Doğaya kronolojik ve tarihsel bir perspektif sunacak (evrim, doğa tarihi vb.) konulara ise yer verilmemektedir.

Doğa ve evreni araştıran bilim dallarının (astronomi, kimya, yer bilimleri, fizik vb.) temadaki varlığı açık değildir. Söz konusu bilimler kavramsal olarak temada yer almamakta, ancak ilişkili oldukları konular aracılığıyla kısmen sezilebilmektedir. Benzer şekilde doğa ve evren bilimlerinin dayandığı olaylar ve olgular da net bir şekilde işlenmemiştir. Doğa ve evrenin canlı ve cansız unsurları, çeşitlilik açısından yeterince temsil edilmemiştir. Teleskop, mikroskop, fotoğraf makinesi vb. araçlarla doğanın ve evrenin incelenmesine ve araştırılmasına değinilmemiştir.

Doğa tarihi açısından insanlar doğaya içgüdüsel olarak yakın olma eğilimindedir. Ancak bu eğilime rağmen sanayi ve teknolojinin gelişimi, insan ile doğa arasında bir mesafe oluşturmuştur. Şehirleşmeyle fiziksel, teknolojiyle zihinsel ve duygusal olarak doğadan uzak kalmış çocuklar kişisel gelişimlerinde doğaya ihtiyaç duymaktadır. Çocukların bu ihtiyaçları bir noktaya kadar fiziksel olarak karşılanabilmekte iken daha fazlası için belirli araçlardan 
O, Turhan, B, Baş ve F, Karaca Turhan/ Pamukkale Üniversitesi Eğitim Fakültesi Dergisi, 52, 31-58, 202147

(internet, televizyon, kitap vb.) yardım alınmaktadır. Bu temada doğa, ağırlıklı olarak çocukların fiziksel olarak görebileceği, duyabileceği, hissedebileceği, kısaca tecrübe edebileceği unsurlardan oluşmaktadır. $\mathrm{Bu}$ durumda tema çocukların okumaya motive olmasına ve doğa bilinci kazanmasına yardımcı olmakta, ancak doğal dünyasının zenginleşmesine katkı sağlamamaktadır. Tema boyunca bahsedilen eksiklikler, temanın çocuğun doğal zekâsını -çoklu zekâ türü- geliştirme potansiyelini sınırlandırmaktadır.

\section{Vatandaşlık}

Vatandaşlık temasının içeriğgi şu şekilde sıralanmaktadır: insan hakları (\%26,5), özgürlükler $(\% 13,1)$, sorumluluk $(\% 10,6)$, adalet $(\% 7,5)$, iş birliği $(\% 7,0)$, üretme $(\% 5,9)$, tüketimharcama (\%5,7), göç $(\% 4,6)$, çalışma $(\% 4,4)$, işsizlik ve geçim sıkıntısı $(\% 3,6)$, eşitlik $(\% 3,4)$, emek (\%2,8), göçmenlik (\%2,8), paylaşma (\%1,5), hukukun üstünlüğ̈̈ $(\% 0,3)$, vergi bilinci $(\% 0,3)$.

Vatandaşlık temasında insan hakları, temel demokratik değerler ve toplumsal değerler-erdemler odak noktayı oluşturmaktadır. Vatandaşlık, aynı zamanda ekonomik yükümlülükler ve ekonomik zorluklar ekseninde de yansıtılmaktadır. Son olarak ulusal ve evrensel olarak günümüzün önemli vatandaşlik unsurlarından olan göç ve göçmenlik konularına da çocuk kitaplarında yer verilmektedir.

Temada vatandaşlık; hukuk ve demokrasi temelinde ele alınmakta, ekonomik ve sosyal bir kavram olarak da işlenmektedir. Vatandaşlık eğitiminin de ana unsurlarından bazılarını demokrasi, hukuk, sosyal yapı, ekonomi alanları oluşturmaktadır. $\mathrm{Bu}$ nedenle çocuk kitaplarındaki yaklaşım olumlu olarak değerlendirilebilir. Aynı zamanda ekonomik zorluklar ve göç konuları, vatandaşlığın bazı toplumsal gerçeklerini göstermesi açsından değerlidir. Ancak temada vatandaşlığa ekonomik açıdan ödev ve sorumluluklar yüklendiği için klasik-geleneksel bir yaklaşımın sergilendiğini de eklemek gerekmektedir.

Temada anayasal, demokratik vatandaşlığın görünür olduğu söylenebilir. Ancak tema birçok vatandaşlık yaklaşımından (ulusal, küresel, sosyal, dijital, ekolojik, çok kültürlü vatandaşlık vb.) yoksundur. $\mathrm{Bu}$ doğrultuda temanın, bahsi geçen sınırlılıklar dâhilinde, vatandaşlık eğitimi için kaynak olabileceği söylenebilir.

\section{Millî Kültürümüz}

Millî Kültürümüz temasının içeriği şu şekilde sıralanmaktadır: dĕgerlerimiz (\%23,7), kültürel miras (\%16,2), yurdumuz (\%16,2), Türkçe (\%8,5), Türk kültürü (\%8,2), vatan 
$(\% 7,7)$, gelenekler $(\% 5,1)$, şehirlerimiz $(\% 5,1)$, tarihî mekânlar $(\% 2,3)$, tarihî eserlerimiz $(\% 2,1)$, insan ilişkileri $(\% 1,8)$, tarihî şahsiyetler $(\% 1,3)$, bayramlar-dinî bayramlar $(\% 0,5)$, mekânlar (\%0,3), millî bayramlar (\%0,3), sıla (\%0,3), hikayeler $(\% 0,3)$, Türk mutfă̆ $(\% 0,3)$.

Millî Kültürümüz temasında tekil olarak değerler, kültürel miras ve yurdumuz konularına ağırlık verilmiştir. Temadaki konular kümülatif olarak incelendiğinde manevi bağ, tarihi ve kültürel unsurlar, yerleşim ve mekân, dil odaklı konuların önemli ölçüde işlendiği görülmektedir. Temada Türk kültürü, geleneksel bir perspektifle öncelikle sosyoloji alanından, daha sonra tarih, mimarlık, coğrafya, dil alanlarından destek alınarak işlenmiş; spor, sanat, siyaset, ekonomi, askerlik, folklor, mutfak, giyim-kuşam, eşya-alet vb. birçok kültürel alan göz ardı edilmiştir.

Kültür kavramı, bir topluma ait maddi ve manevi tüm unsurları temsil etmektedir ve bu unsurlar arasında değer kıyaslaması yapılmaması gerekmektedir. Bu nedenle çocukların topluma ait kültürel ögeleri bütüncül bir şekilde öğrenmesi önemlidir. Kapsamlı ve derin yapısından dolayı kültürün öğrenilmesinde sosyal hayat ve kişiler arası etkileşimler yeterli değildir. Bu noktada basılı, görsel ve işitsel materyaller, öğrenime aracılık etmektedir. Böylece çocuk kitapları, kültürel aktarımda işlevsel rol kazanmaktadır. Ancak temada Türk kültürüne ait ögeler homojen dağılım göstermemekte ve dengeli bir şekilde işlenmemektedir. Söz konusu durumlar, temanın kültür aktarımındaki potansiyelini oldukça sınırlamaktadır. Ancak temada bazı önemli kültürel alanlar işlendiğinden, bahsedilen sınırlılıklar dâhilinde kültür aktarımı için kaynak olarak kullanılabilir.

\section{Sanat}

Sanat temasının içeriği şu şekilde sıralanmaktadır: edebiyat $(\% 38,2)$, söz sanatları $(\% 15,7)$, sanat (\%14,7), müzik (\%8,9), sanatçı (\%4,7), estetik (\%4,2), sinema / belgesel / dizi $(\% 2,6)$, tiyatro $(\% 2,1)$, geleneksel sanatlar $(\% 1,6)$, gölge oyunu $(\% 1,6)$, fotoğraf $(\% 1,0)$, resim $(\% 1,0)$, sahne sanatlarl $(\% 1,0)$, festival $(\% 0,5)$, minyatür $(\% 0,5)$, pandomim $(\% 0,5)$, yenilikçi düşünme (\%0,5), dans (\%0,5).

Sanat temasında, tema isminin konu olarak verildiği kayda değer sayıda çocuk kitabı bulunmaktadır. İçeriği belli olan konular, sanat dallarıyla ilgilidir. Temada sanatsal yeteneği, beceriyi, duyarlılığı veya unsurları işaret eden konular düşük düzeyde işlenmiştir. Temaya tekil olarak edebiyat konusu hâkimdir. Kümülatif olaraksa temada dil sanatlarının hakimiyeti göze çarpmaktadır. Bu sanat dalını sırasıyla ses sanatları, dramatik sanatlar, 
O, Turhan, B, Baş ve F, Karaca Turhan/ Pamukkale Üniversitesi Eğitim Fakültesi Dergisi, 52, 31-58, 202149 görsel sanatlar, hareket sanatları takip etmektedir. Ancak ses sanatları hariç diğer sanat dallarının temadaki varlığı zorlukla hissedilmektedir. Temada göz ardı edilen sanat dallarını mekân sanatları, hacim sanatları, geleneksel Türk sanatları, yeni medya sanatları, sokak sanatları şeklinde örneklendirmek mümkündür.

Dil ve edebiyat ürünü olan çocuk kitapları, tematik olarak da aynı sanatı temsil etmektedir. $\mathrm{Bu}$ durum çocukların teorik ve pratik olarak edebiyatı tecrübe etmelerini sağlamaktadır. Ancak bu durum, sanat dalları arasındaki doğal ve kuvvetli bağdan tema kapsamında faydalanılmadığını göstermektedir. Fen ve sosyal bilimlerden farklı olarak sanat, çocukların bilgi ihtiyaçları haricinde ruhsal ve duyuşsal ihtiyaçlarına karşılık bulacağı ideal bir alandır. Sanat; 21. yüzyıl becerilerini (yaratıcılık, eleştirellik, üretkenlik, iletişim) desteklemekte, farklı zekâ türlerine (müziksel, içsel, uzamsal, kinestetik vb.) hitap etmekte, çeşitli ortamlara (sınıf, galeri, müze, atölye, sergi vb.) adapte edilebilmekte ve işlevsel bir eğitim aracı olarak kullanılabilmektedir. Ancak temada farklı sanat dallarına yeterince yer verilmemiş, sanatın farklı boyutları işlenmemiştir. Bu nedenle tema, sanat yoluyla eğitim ve sanatsal gelişim için kayda değer bir firsat sunmamaktadır.

\section{Sağlık ve Spor}

Sağlık ve Spor temasının içeriği şu şekilde sıralanmaktadır: sağlık ve spor $(\% 29,8)$, hastalıksakatlık-engel (\%24,0), spor-spor kültürü (\%15,7), yaşam ve ölüm (\%14,9), sağlıkl yaşam $(\% 6,6)$, beden sağglı̆̆ (\%2,5), sağlıklı beslenme (\%2,5), beslenme (\%1,7), ilaç kullanımı $(\% 0,8)$, sportmenlik (\%0,8), să̆llk hizmeti $(\% 0,8)$.

Sağlık ve Spor temasında, tema isminin konu olarak verildiği çok sayıda çocuk kitabı bulunmaktadır. Sağlık alt temasına sağlık sorunları hâkimdir. Aynı zamanda beden sağlığıyla ilgili konular da temada işlenmektedir. Spor alt temasında ise spor-spor kültürü işlenmektedir.

Alt temada sağlık sorunlarının öne çıktığını, sağlıklı olmanın ise daha arka planda kaldığını söylemek mümkündür. Uzuv eksikliği, görme engeli, disleksi, otizm, down sendromu, ölüm gibi hassas konuların işlenmesi çocukların farkındalık kazanması ve hayatın gerçeklerini tecrübe etmesi açısından önemlidir. Bedensel ve ruhsal açıdan sağlıklı olma konularının da en az sağlık sorunları kadar üzerinde durulması gerekmektedir. Ancak temada bedensel sağlık az işlenmiş, ruhsal sağlık ise hiç işlenmemiştir. Ortaokul öğrencileri, birçok konuda olduğu gibi sağlık konusunda da rehberliğe ihtiyaç duymaktadır. Bu rehberlik sürecinde broşür, el kitapçığı gibi yazılı metinler sıkça kullanılmaktadır. Buna göre çocuk 
kitapları da benzer işlevle kullanılabilir. Ancak sağlık konusu bütüncül ve dengeli bir şekilde işlenmediği için, alt tema sağlık eğitimi ve rehberliği açısından kayda değer firsat sunmamaktadir.

Çağdaş dünyada modernleşme çocukların fiziksel aktivitelerini, şehirleşme ve nüfus yoğunluğu ise çocukların oyun ve spor alanları azaltmıştır. Bu nedenle çocukların sporu tecrübe etmeleri ve spor kültürü kazanmaları için medya araçları daha önemli bir hale gelmiştir. Bu bağlamda televizyon kanalları, bilgisayar oyunları, internet yayınları daha geniş ve işlevsel kullanıma sahiptir. Ancak çocuk kitaplarının da kullanılması mümkündür. Çocuk kitapları incelendiğinde alt temada tekil olarak futbola odaklanıldığı, diğer spor dallarına yeterince değinilmediği görülmektedir. Bu doğrultuda çocukların spora olan doğal ilgisinden uygun bir şekilde faydalanılamadığı söylenebilir. Alt temanın diğer bölümünü oluşturan spor kültürü, spor dallarına bütüncül ve girift bir yaklaşımı (bedensel, zihinsel ve duygusal) temsil etmektedir. Bu nedenle alt temada spor kültürünün işlenmesi, salt spor dallarının işlenmesinden daha önemlidir. Ancak spor kültürüne de gereken önem verilmemiştir. Söz konusu eksiklikler nedeniyle, alt temanın çocukların spor dünyalarını genişletme ve spor kültürünü geliştirme potansiyelinin sınırlı kaldığı söylenebilir.

\section{Hak ve Özgürlükler}

Hak ve Özgürlükler temasının içeriği şu şekilde sıralanmaktadır: hak ve özgürlükler (\%29,8), özgürlükler-yasaklar (\%23,7), eşitlik (\%10,7), eğitim hakkı (\%6,9), insan hakları $(\% 4,6)$, çocuk hakları $(\% 3,8)$, din ve vicdan özgürlüğ̈̈ $(\% 3,8)$, bireysel haklar $(\% 3,1)$, inanç hakkı (\%3,1), düşünce özgürlügü (\%1,5), hayvan hakları (\%1,5), merhamet (\%1,5), haksılık (\%1,5), demokrasi (\%0,8), ifade özgürlüğü (\%0,8), özel hayatın gizliliği $(\% 0,8)$, temel hak ve özgürlükler (\%0,8), toplumsal cinsiyet eşitliği (\%0,8), haklara saygı (\%0,8).

Hak ve Özgürlükler temasının büyük bir bölümü, tema olabilecek kadar kapsamlı ve içeriği belirsiz konulardan oluşmaktadır. Diğer konuların ise az sayıda çocuk kitabında yer aldığı görülmektedir. Bu konular kümülatif olarak değerlendirildiğinde kişisel ve siyasal haklardan meydana gelen birinci kuşak hakların odak noktayı oluşturduğu görülmektedir. Ekonomik ve sosyal haklardan meydana gelen ikinci kuşak haklar ise çocuk kitaplarında arka planda kalmıştır. Halk ve dayanışma haklarından meydana gelen üçüncü kuşak haklara ise yer verilmemiştir. Çocuk hakları ve hayvan hakları da çok az işlenmiştir.

Temada insanların hak ve özgürlükleri işlenirken, diğer canlıların hak ve özgürlükleri göz ardı edilmiştir. Temanın büyük bir bölümünü oluşturan konuların içerik açısından 
O, Turhan, B, Başv ve F, Karaca Turhan/ Pamukkale Üniversitesi Eğitim Fakültesi Dergisi, 52, 31-58, 202151 belirsiz oluşu, temadaki eğilimlerin net bir şekilde tespit edilmesini engellemektedir. İçeriği açık olan konular incelendiğinde kişisel ve siyasal kavramların öne çıktığını; sosyal, ekonomik, kolektif kavramların ise arka planda kaldığını açıkça görmek mümkündür. Temada işlenen kişisel ve siyasal hak ve özgürlükler ise birçok alt konudan yoksundur. Bahsedilen eksikliklerden dolayı temanın; çocukların şu an sahip olduğu ve gelecekte sahip olacağı hak ve özgürlükleri öğrenmesini, başka insanların ve diğer canlıların hak ve özgürlüklerinin olduğunu fark etmesini, böylece bilinçli vatandaşlar hâline gelmesini sağlama potansiyeli oldukça sınırlıdır.

\section{Bilim ve Teknoloji}

Bilim ve Teknoloji temasının içeriği şu şekilde sıralanmaktadır: bilim ve teknoloji $(\% 24,1)$, keşif ve icatlar (\%12,1), medya-sosyal medya (\%9,2), iletişim (\%8,5), fen bilimleri $(\% 8,5)$, teknoloji $(\% 7,8)$, bilim okuryazarlı̆̆ $(\% 6,4)$, sosyal bilimler (\%4,3), internet $(\% 2,8)$, etik $(\% 2,1)$, haberleşme $(\% 2,1)$, hayal gücü $(\% 2,1)$, merak duygusu $(\% 2,1)$, olay $(\% 2,1)$, ulaşım $(\% 2,1)$, olgu $(\% 1,4)$, bilim insanları $(\% 0,7)$, yenilikçilik $(\% 0,7)$, bilgisayar oyunu $(\% 0,7)$.

Bilim ve Teknoloji temasında, tema isminin konu olarak verildiği çok sayıda çocuk kitabı bulunmaktadır. Temaya teknolojik gelişmelerin hâkim olduğu görülmektedir. Ayrıca bu teknolojik gelişmelerin etkilediği alanlara da yer verilmektedir. Bilim alt temasında ise fen bilimleriyle ilgili konular (matematik, biyoloji vb.) daha çok, sosyal bilimlerle ilgili konular (arkeoloji, tarih vb.) daha az işlenmektedir. Ayrıca fen bilimleriyle bağlantılı olarak olay, olgu ve bilim insanları konularına kısmen yer verilmektedir. Son olarak bilim ve teknolojinin irdelendiği kavramların ve bilim ve teknolojinin gelişimi için gerekli olan becerilerin kısmen işlendiği de görülmektedir.

Temada bilim ve teknolojinin çeşitli yönlerini aydınlatan kavramlar ele alınmaktadır. Ancak bu kavramların işlenme düzeyleri arasındaki önemli farklılar, kavram çeşitliliğinin çocuk kitaplarına yansıtılmadığını göstermektedir. Buna göre temada, çocukların teknoloji (çoğunlukla bilgisayar, internet) kullanıcısı ve tüketicisi olmaya indirgendiği söylenebilir. Çünkü temada bilim/teknoloji yetkinliklerine ve becerilerine, bilim/teknoloji ve matematik okuryazarlığına çok az yer verilmiştir. Aynı zamanda çocukların eğitim sürecini doğrudan etkileyen dijital yetkinlikler hiç işlenmemiştir. Ayrıca bilim ve teknoloji üretimi bağlamındaki konular da göz ardı edilmiştir.

Temada bilim dalları açısından net bir eğilim bulunmamaktadır. Bilim dalları ise çoğunlukla ismen sunulmuştur. Ortaokul düzeyindeki öğrencilerin bilime olan ilgisi mesleki 
tercihlerde (mühendis, doktor, bilim insanı vb.) kendini göstermektedir. Bilim dalları ile kariyer eğilimleri arasında ilişki kurulması, çocukların mesleki gelişimine katkı sağlayacak ve okumaya motive olmasını sağlayacaktır. Ancak temada bu firsattan yararlanılmamıştır. Temada temel bilimsel beceriler ve bilim tarihi de işlenmemektedir. Tespit edilen eksikler doğrultusunda temanın bilimsel sürecin öğrenilmesi ve bilimsel bilgi ve farkındalık kazanılması için fırsat vermediği öne sürülebilir.

\section{Okuma Kültürü}

Okuma Kültürü temasının içeriği şu şekilde sıralanmaktadır: okuma kültürü $(\% 33,6)$, okumak (\%33,6), edebî şahsiyetler (\%6,9), okuma sevgisi (\%6,9), kitaplar (\%4,6), okuma serüveni (\%4,6), kütüphaneler (\%3,8), okuma alışkanlı̆̆ $(\% 3,8)$, kitabevi (\%1,5), bilgi okuryazarliğl $(\% 0,8)$.

Okuma Kültürü temasında, tema isminin konu olarak verildiği çok sayıda çocuk kitabı bulunmaktadır. Bu durum zaten sınırlı çocuk kitabında işlenen temayı daha da sınırlamaktadır. İçeriği net olan konularda okumanın zihinsel, psikolojik ve fiziksel unsurlarına yer verilmiştir. Ancak temada okuryazarlık türlerinin, metin formatlarının, okuma amacının yoksunluğu göze çarpmaktadır. Her kültürel unsur gibi okuma kültürü de bireyin zihinsel ve psikolojik dünyasından çok daha fazlasını kapsamaktadır. Ancak tema, okuma kültürünün kişilerarası ve sosyal yönünü ortaya koyacak şekilde işlenmemiştir.

Çok boyutlu ve bütüncül bir şekilde işlenmediği için, temanın çocukların okuma kültürünü geliştirme potansiyeli pek çok açıdan oldukça sınırlı kalmaktadır.

\section{Millî Mücadele ve Atatürk}

Millî Mücadele ve Atatürk temasının içeriği şu şekilde sıralanmaktadır: Atatürk $(\% 36,4)$, Cumhuriyet (\%18,2), millî mücadele (\%15,2), millî kimlik (\%12,1), vatanseverlik (\%12,1), cesaret (\%3,0), kahramanlı $(\% 3,0)$.

Millî Mücadele ve Atatürk temasına Atatürk’ün (eğitim, sevgi, kişilik özellikleri bağlamında) hâkim olduğu görülmektedir. Temada cumhuriyetle birlikte millî mücadelenin, millî duyguların ve millî kimliğin de işlendiği görülmektedir.

Temanın Atatürk'ün kişisel ve toplumsal bir perspektiften tanınmasını, millî mücadele ve cumhuriyet dönemindeki rolünün ve öneminin anlaşılmasını sağlayacak düzeyde işlenmediği açıktır. Benzer şekilde millî mücadelenin hangi cephelerde, hangi 
O, Turhan, B, Baş ve F, Karaca Turhan/ Pamukkale Üniversitesi Eğitim Fakültesi Dergisi, 52, 31-58, 202153

şartlar ve imkanlar dâhilinde, hangi toplumsal değerlere bağlı kalınarak yürütüldügünün öğrenilmesini sağlayacak potansiyeli de bulunmamaktadır.

\section{Sonuç}

Türk çocuk edebiyatı; çocuk gelişimi, çocuk eğitimi, çeşitlik açısından hem olumlu hem de olumsuz tematik özelliklere sahiptir. Bu nedenle Türk çocuk edebiyatının tematik yeterliliği ile ilgili kesin bir hüküm vermek doğru olmayacaktır.

Teorik olarak geniş bir kapsama ve kavramsal ağa sahip olan erdemler, birey ve toplum, kişisel gelişim, iletişim, duygular, çocuk dünyası gibi temalar çocuk kitaplarında daha çok işlenmektedir. Fakat özel konu alanlarından meydana geldiği için daha sınırlı bir kapsama ve kavramsal ağa sahip olan hak ve özgürlükler, sağlık ve spor, bilim ve teknoloji, sanat, okuma kültürü, millî mücadele ve Atatürk gibi temalar ise daha düşük düzeyde işlenmektedir. Ulaşılan bu sonuçlar, kapsamlı bir örneklem üzerinde yapılmış diğer çalışmaların sonuçlarıyla benzerlik göstermektedir (Arslantaş, 2003; Aydın, 2019; Baş, 2011). Bu noktada Türk çocuk edebiyatında temaların teorik kapasiteleri doğrultusunda işlendiği, benzer konulara yer verildiği, özel konu alanlarının işlenmesi için ekstra çaba sarf edilmediği ifade edilebilir.

Çocuk kitaplarında daha çok işlenen temaların (erdemler, kişisel gelişim, iletişim, duygular vb.) çocuk gelişimini destekleme potansiyeli bulunmaktadır. Ancak diğer temaların (sanat, sağlık ve spor, bilim ve teknoloji, hak ve özgürlükler, okuma kültürü vb.) çocuk gelişimini destekleyecek potansiyelinin olmadığı veya çok sınırlı bir potansiyele sahip olduğu görülmektir. Temalarda genellikle tek bir gelişim alanı işlenmektedir. Kişisel gelişim ve çocuk dünyası temalarında ise gelişim alanları daha bütüncül bir şekilde ele alınmaktadır. Temalar kümülatif olarak değerlendirildiğinde, sosyal, zihinsel, duygusal ve ahlaki gelişimin öne çıktığı görülmektedir. Fakat özel bir gelişim alanının çoğunlukla bazı konular çevresinde, dar bir bakış açısıyla ve tek boyutlu olarak işlenmesi oldukça büyük ve önemli bir problemdir. Çocuk kitapları disiplinler arası yaklaşıma göre değerlendirildiğinde, temaların çeşitlilik göstermediği anlaşılmaktadır. Bu kitaplar, Türkçe ve sosyal bilgiler başta olmak üzere bazı sözel dersler (insan hakları, yurttaşlık ve demokrasi, rehberlik ve kariyer planlama, hukuk ve adalet vb.) için uygun içerik sunmaktadır. Ancak bu kitapların sayısal (fen bilgisi, matematik, bilişim teknolojileri ve yazılım, teknoloji ve tasarım vb.), sanatsal (müzik, görsel sanatlar vb.) ve fiziksel (beden eğitimi ve oyun vb.) dersler için kullanılabilirliği sınırlıdır. Çocuk kitaplarının iletişimsel, sosyal ve vatandaşlık temelli 
yetkinlikleri geliştirme potansiyeli bulunmaktadır. Diğer taraftan matematik, bilim, teknoloji, inisiyatif alma, girişimcilik, kültürel farkındalık, öğrenmeyi öğrenme üzerine yapılandırılan yetkinlikleri destekleme potansiyeli ise sınırlıdır. Ayrıca eğitim-öğretim sürecinde önem verilen kök değerlerin (adalet, arkadaşlık, dürüstlük, sayg1, sevgi, sorumluluk) temalarda öne çıkması, çocuk kitaplarının eğitsel niteliğini arttırmaktadır. Son olarak kitaplarda çocuk eğitimi açısından okul ve müfredat bağlamında olmayan bazı kazanımların amaçlandığı sezilmektedir. Bunların arasında çocuğun ahlaki değerleri olan bir insan olması, çeşitli açılardan kendini geliştirmesi, toplumsal hayata hazırlanması öne çıkmaktadır.

Çocukların geneline hitap eden, çocukluk tecrübeleriyle ilgili, çocukların ilgisini çekebilecek birçok konu (aile, arkadaşlar, duygular, hayaller, hayvanlar, canlılar, okul, çevre, büyüme-olgunlaşma vb.) çocuk kitaplarında yoğun bir şekilde işlenmektedir. Ancak özel konu alanlarının (bilim, teknoloji, hobi, spor, moda, sanat, tarih, ülkeler, farklı kültürler, ünlü kişiler vb.) göz ardı edilmişliği ve yoksunluğu tematik çeşitlilik ve özel ilgi alanları olan öğrenciler açısından önemli bir eksikliktir. Ayrıca çocukların ilgisini çeken metin türü temelli birçok tema (merak, gizem, mizah, macera, olağanüstülük vb.), çocuk kitaplarında işlenmektedir. Ancak bu alana ait bazı temalar (korku, gerilim, bilimkurgu, hayatta kalma, romantizm vb.) göz ardı edilmiştir. Son olarak temalarda hayatın acı gerçekleri, baş edilmesi gereken olumsuz durumlar, zor ve kötü tecrübeler (ölüm, ayrılık, mutsuzluk, yalnızlık, kötü alışkanlıklar, fiziksel ve sözlü şiddet, aile ve akran baskısı, kaygı, ruhsal problemler, aşk acısı, başarısızlık vb.) düşük düzeyde işlenmiş, çocuklara yönelik korumacı bir tutum sergilenmiştir.

Etik Kurul İzin Bilgisi: Bu çalışma ölçek ve anket uygulaması gerektirmediği için etik kurul iznine gerek duyulmamıştır.

Yazar Çıkar Çatışması Bilgisi: Yazarlar çıkar çatışması olmadığını beyan etmektedir.

Yazar Katkısı: Yazarlar çalışmaya eşit oranda katkı sağlamıştır. 
O, Turhan, B, Baş ve F, Karaca Turhan/ Pamukkale Üniversitesi Eğitim Fakültesi Dergisi, 52, 31-58, 202155

\section{Kaynakça}

Akbayır, S. ve Şahin, Ş. (2005). Yaş gruplarına göre çocuklar için edebiyat. Hece. 104-105, 190-204.

Anderson, N. A. (2006). Elementary children's literature: The basics for teachers and parents. Boston, MA: Pearson.

Appel, M., \& Richter, T. (2007). Persuasive effects of fictional narratives increase over time. Media Psychology, 10(1), 113-134.

Arslantaş, H. (2003). Cumhuriyet sonrası (1981-2001) çocuk romanlarında tema, dil ve eğitim öğeleri. Yayımlanmamış yüksek lisans tezi, Dokuz Eylül Üniversitesi Eğitim Bilimleri Enstitüsü, İzmir.

Aydın, E. (2019). Türk edebiyatındaki ödüllü çocuk romanlarında temalar (1948-2016). Yayımlanmamış doktora tezi, Sakarya Üniversitesi Eğitim Bilimleri Enstitüsü, Sakarya.

Bailey, K. (1994). Methods of social research. New York: The Free Press.

Barone, D. M. (2010). Children's literature in the classroom: Engaging lifelong readers. New York, NY: Guilford Press.

Baş, B. (2011). İlköğretim yüz temel eserin Türkçe dersi öğretim programındaki temalar açısından analizi. Mustafa Kemal Üniversitesi Sosyal Bilimler Enstitüsü Dergisi, $8(15), 175-200$.

Bee, H. ve Boyd, D. (2009). Çocuk gelişim psikolojisi. İstanbul: Kaknüs Yayıncılık.

Berger, K. S. (2000). The developing person through childhood and adolescence. New York: Worth Publishers.

Bucher, K. T., \& Hinton, K. (2014). Young adult literature: Exploration, evaluation, and appreciation. Upper Saddle River, NJ: Prentice Hall.

Camp, D. (2007). Who's reading and why: Reading habits of 1 grade through graduate students. Reading Horizons Journal, 47(3), 251-258.

Creswell, J. W. (2016). Nitel araştırma yöntemleri: Beş yaklaşıma göre nitel araştırma ve araştırma deseni. Ankara: Siyasal Kitabevi. 
Darigan, D., Tunnell, M., \& Jacobs, J. (2002). Children's literature: Engaging teachers and children in good books. Upper Saddle River, NJ: Prentice Hall.

Davila, D., \& Patrick, L. (2010). Asking the experts: What children have to say about their reading preferences. Language Arts, 87(3), 199.

Davis, J. C., \& Palmer, J. (1992). A strategy for using children's literature to extend the social studies curriculum. Social Studies, 83(3), 125-128

Doğan, Y. (2007). İlköğretim çağındaki 10-14 yaş grubu öğrencilerinin gelişim özellikleri. Uludağ Üniversitesi Fen-Edebiyat Fakültesi Sosyal Bilimler Dergisi, 8(13), 155-187.

Estes, T. H., \& Vasquez-Levy, D. (2001). Literature as a source of information and values. Phi Delta Kappan, 82(7), 507-512.

Galda, L., \& Cullinan, B. (2002). Literature and the child. Belmont, CA: Wadsworth.

Gander, M. J. ve Gardiner, H. W. (2004). Çocuk ve ergen gelişimi. Ankara: İmge Kitabevi Yayınları.

Halverson, D. (2011). Writing young adult fiction for dummies. Indiana: Wiley Publishing

Holsti, O. R. (1969). Content analysis for the social sciences and humanities. Reading, MA: Addison-Wesley.

Hopkins, E., \& Weisberg, D. S. (2017). The youngest readers' dilemma: A review of children's learning from fictional sources. Developmental Review, 43, 48-70.

Horning, K. T. (1997). From cover to cover: Evaluating and reviewing children's books. New York: HarperCollins.

Huck, C. S., Hepler, S., \& Hickman, J. (1987). Children's literature in the elementary school. NY: Holt, Rinehart and Winston.

Ivey, G., \& Johnston, P. H. (2013). Engagement with young adult literature: Outcomes and processes. Reading Research Quarterly, 48(3), 255-275.

Kim, J. Y., \& Anderson, T. (2011). Reading across the curriculum: A framework for improving the reading abilities and habits of college students. Journal of College Literacy \& Learning, 37, 29-40.

Krashen, S. (2005). Free voluntary reading: New research, applications, and controversies. In G. Poediosoedarmo (Eds.), Innovative approaches to reading \& writing 
O, Turhan, B, Baş ve F, Karaca Turhan/ Pamukkale Üniversitesi Eğitim Fakültesi Dergisi, 52, 31-58, 202157 instruction, anthology series 46(pp. 1-9). Republic of Singapore: SEAMEO Regional Language Centre.

Krashen, S. (2006). Free reading: Is it the only way to make kids more literate?. School Library Journal, 52(9), 42-45.

Lincoln, Y. S., \& Guba, E. G. (2013). The constructivist credo. New York, NY: Left Coast Press.

Lombard, M., Snyder-Duch, J., \& Bracken, C. C. (2002). Content analysis in mass communication: Assessment and reporting of intercoder reliability. Human Communication Research, 28(4), 587-604.

Lynch-Brown, C. G., Tomlinson, C. M., \& Short, K. G. (2010). Essentials of children's literature. New York: Pearson.

McClure, A. A., Garthwait, A. \& Kristo, J. V. (2015). Teaching children's literature in an era of standards. Boston: Pearson.

Merriam, S. B., \& Tisdell, E. J. (2015). Qualitative research: A guide to design and implementation. San Francisco: Jossey-Bass.

Miles, M. B., \& Huberman, A. M. (1994). An expanded sourcebook qualitative data analysis. California: Sage Pablication.

Millî Eğitim Bakanlığı (MEB). (2019). Türkçe Dersi Öğretim Programı (İlkokul ve Ortaokul 1-8. Sinıflar). Ankara: Millî Eğitim Bakanlığı Yayınları.

Morgan, D. N., \& Wagner, C. W. (2013). What's the catch?: Providing reading choice in a high school classroom. Journal of Adolescent \& Adult Literacy, 56(8), 659-667.

Nuba, H., Sheiman, D., \& Searson, M. (2016). Children's literature: Developing good readers. London: Routledge.

Pantaleo, S. (2002). Children's literature across curriculum: An Ontario Survey. Canadian Journal of Education, 27(23), 211-230.

Patton, M. Q. (2014). Nitel araştırma ve değerlendirme yöntemleri. Ankara: Pegem Yayıncilık.

Ross, E. P. (1994). Using children's literature across the curriculum. Fastback 373. Bloomington, IN: Phi Delta Kappa. 
Samuels, B. G. (1989). Young adults' choices: Why do students" really like" particular books?. Journal of Reading, 32(8), 714-719.

Sawyer, W. (2000). Growing up with literature. Albany, NY: Delmar.

Schanzer, R. (1996). Evaluating and selecting literature for children. Boston: Houghton Mifflin Company.

Smith, C. B. (1991). Using literature across the curriculum. Reading Teacher, 44(7), 516.

Tomlinson, C. M., \& Lynch-Brown, C. (2007). Essentials of young adult literature. Boston: Pearson.

Tunnell, M. O., \& Jacobs, J. S. (2007). Children's literature, briefly. Upper Saddle River, NJ: Pearson.

Wilhelm, J. (2015). Let them read trash!. English in Aotearoa, 85, 16-22.

Wolf, S. (2004). Interpreting literature with children. Mahwah, NJ: Lawrence Erlbaum.

Yıldırım, A. ve Şimşek, H. (2013). Sosyal bilimlerde nitel araştırma yöntemleri. Ankara: Seçkin Yayıncılık.

Yin, R. K. (2003). Case study research: Design and method. Thousand Oaks, London, New Delhi: SAGE Publications. 


\title{
Examining the Themes of Turkish Children's Literature Through Book Catalogues
}

\author{
Osman TURHAN*, Bayram BAŞ ${ }^{* *}$, Fatma KARACA TURHAN***
}

• Received: 15.09.2020 Accepted: 13.10.2020 • Online First: 15.10.2020

\begin{abstract}
This study sets out to identify themes in Turkish children's literature. Accordingly, Turkish children's literature was examined in terms of child development and education. This study was designed as a case study. Six hundred and sixty-five Turkish children's books were selected from four publishing houses using criterion sampling, and book catalogs were reviewed. Qualitative and quantitative content analysis was administered on the selected children's books according to the Turkish course curriculum themes. Sixteen themes were identified in the children's books. General themes (individual and society, virtues, etc.) were covered in children's books more, while special themes (science and technology, art, etc.) were covered less. When the themes were evaluated in terms of child development, child education, and diversity, some positive and negative results were obtained. Some themes in children's books were not qualified to contribute to child development. Other themes had the potential to support social, mental, emotional, and moral development. However, development areas were not covered in a comprehensive and detailed manner. Children's books had contents suitable for some verbal lessons and verbal competencies in terms of teaching. The same was not true for other courses and competencies. Additionally, children's books had the potential to support children's education on extra-curricular grounds. Finally, a thematically positive and partly limited world was presented in children's books. However, this thematic world displayed may attract the attention of children.
\end{abstract}

Keywords: Turkish children's literature, book catalogues, theme, child development, child education.

\section{Cited:}

Turhan, O., Baş, B., \& Karaca Turhan, F. (2021). Examining the Themes of Turkish Children's Literature Through Book Catalogues. Pamukkale University Journal of Education, 52, 3158.doi:10.9779.pauefd.794327

\footnotetext{
* Res. Assist., Yildiz Technical University, osmant@yildiz.edu.tr, ORCID: 0000-0003-4800-5786

** Assoc. Prof. Dr., Yildiz Technical University, bbas@yildiz.edu.tr, ORCID: 0000-0003-3569-9395

*** Lect., Yildiz Technical University, fkaraca@yildiz.edu.tr, ORCID: 0000-0001-9665-1032
} 


\section{Introduction}

Combining all literary elements (character, plot, time and space, style, and tone), the theme places a reader at its center and gains its true meaning in the reader's mind (Horning, 1997). Hence, it has a deeper meaning than other literary elements and is more permanent in children's minds (Bucher \& Hinton, 2014, p. 33). It is also the most difficult literary element for children to identify (Barone, 2010, p. 113). The theme is difficult to define as it is based on the reader's experience and exhibits a complicated structure. However, in its simplest form, it can be defined as the author's reason for writing a story or the main idea of a story (Tunnell \& Jacobs, 2007, p. 13). The message from the author to the reader can be reduced to a word or group of words (friendship, the difficulty of loneliness, etc.). However, a sentence that reveals how the author approaches these concepts expresses the theme better. The theme usually spans the whole story. Sometimes it can fit into a single sentence in the story. Secondary themes remain behind the main theme, which has a vague appearance and are more difficult to locate (Anderson, 2006, p. 38). The latent theme structure, which is intertwined and nurtures one another, increases the credibility and literary quality of a storytext (Sawyer, 2000, p. 74).

Children's books consist of real-life issues that reveal human beings' individual and social situations (Wolf, 2004, p. 54). For this reason, they address the parallel worlds of children and feed on the similarity of childhood experiences (McClure, Garthwait \& Kristo, 2015, p. 14), about which children are more interested in reading (Camp, 2007; Samuels, 1989). Accordingly, the changes and necessities of growing up in situations directly related to children's lives and individual relations with family and friends come to the fore in books. However, real life is not always reflected from a positive perspective. Individual and social problems such as death, illness, poverty, bad habits, oppression, exclusion, and violence are also included in children's books (Bucher \& Hinton, 2014; Darigan, Tunnell \& Jacobs, 2002; Halverson, 2011). Still, the themes covered in children's literature are not limited to these. Every important concept which cognitive, psychological, and social development of the child is built on such as learning, individualization, socialization, health, sports, society, communication, science, technology, reading, time and space, culture, right, morality, virtue, emotion, nature, art, etc. (Bee \& Boyd, 2009; Berger, 2000; Doğan, 2007; Gander \& Gardiner, 2004) falls within the thematic scope of children's literature. Through these themes, books help children identify their goals, wishes, and desires, keep their dreams alive, expand their horizons, recognize themselves and shape their personality, discover and 
confront with their emotions, use their mental skills, establish strong relationships with family and friends, develop social skills, understand harsh realities of life (death, separation, sadness, bitterness) and human values, and gain experience in life.

All children possess developmentally similar characteristics. Using only this partnership, literature can reflect the lives of children with different linguistic, racial, and cultural backgrounds (Galda \& Cullinan, 2002, p. 6). For example, secondary school children's lives intersect on "friend, family, romance, gender, sport, hobby, talent, skill, growing up, maturing, excitement, adventure, humor, career, science, technology, animal, life problems, morality, value, culture, role model" (Akbayır \& Şahin, 2005; Huck, Hepler \& Hickman, 1987) based themes. Yet, it does not necessarily mean that all children prefer to read books with similar themes or have similar reading interests. Although there are some similarities in children's reading interests in terms of gender, age, and developmental levels, each child has his/her unique aesthetic taste (Huck et al., 1987). Therefore, attention should be paid to ensuring thematic diversity in children's books (Lynch-Brown, Tomlinson \& Short, 2010, p. 42). In addition to addressing children's interests, new themes should also be aroused by providing thematic diversity (Schanzer, 1996, p. 74). Finally, one should always remember that the process of a child's development as a whole and the parts that make up this process are interrelated. Hence, themes related to the children's physical, mental, emotional, social, etc. development need to be adequately included. This is an expectation of an ideal for the cumulative content of children's books rather than for a single book.

What matters the most for a children's book is that children enjoy reading it (Tomlinson \& Lynch-Brown, 2007, p. 27). However, children's literature has functions other than providing literary and aesthetic pleasure. Reading is primarily a key skill for all courses (Kim \& Anderson, 2011, p. 31). Accordingly, it is possible to use children's books functionally, especially in educational environments designed upon the constructivist approach. Children's books' thematic opportunities are used in courses related to many different disciplines such as social sciences, life sciences, art, physical education, and health (Davis \& Palmer, 1992; Pantaleo, 2002; Ross, 1994; Smith, 1991). Unlike textbooks, children's non-fiction books can provide more in-depth knowledge and a broader perspective on any course subject. A similar situation applies to fiction books for children. In addition, it can be observed that fiction books are a source of more effective, permanent, and functional learning compared to non-fiction ones. Children's non-fiction books provide a much greater depth to anyone subject contrary to the superficial coverage presented in textbooks (Darigan 
et al., 2002, p. 507). A similar situation applies to children's fiction books (Estes \& VasquezLevy, 2001, p. 510). It can also be observed that fiction books are a source of more effective, permanent, and functional learning than non-fiction books (Appel \& Richter, 2007; Hopkins \& Weisberg, 2017).

Independent reading is important for children and dependent (educational) reading (Baş, 2011, p. 179). Therefore, children should be allowed to choose books freely. Because when offered a chance to choose, children prefer books suitable for their developmental level and enjoy reading (Davila \& Patrick, 2010; Wilhelm, 2015). Children who read books of their choice are more motivated to read and improve their reading skills (Ivey \& Johnston, 2013; Krashen, 2005). However, children are often taught through books chosen by others, not their own (Morgan \& Wagner, 2013, p. 660). A similar situation applies to the Turkish education system, which is structured in textbooks. However, in the Turkish Language Curriculum, extracurricular/independent reading is encouraged through non-textual and intertextual reading (MEB, 2019, p. 8). In this direction, children should be guided to reach as many books as possible (Krashen, 2006, p. 46). Children may have difficulties finding books suitable for their age in terms of theme and subject, especially at the secondary school level (Davila \& Patrick, 2010, p. 200). It is possible to select books suitable for the age and interest through book catalogs in which information in terms of theme and subject, book summary, class-age, and theme-subject is available.

Briefly, theme is an important indicator of the nature and content of a book. The personal development of children should thematically support children's literature, and accordingly, it should offer thematic diversity towards different literary tastes of children. Children's literature, both fiction and non-fiction, has the quality of being an educational material that can be used in various courses according to the thematic approach. Independent reading should be given importance due to the academic and aesthetic opportunities it offers, and children should be guided in accessing books that are suitable for them in terms of theme and subject. From this point of view, it is important and necessary to examine children's literature thematically. Against this backdrop, this study aims to explore the themes in Turkish children's literature through book catalogs, which serve as a guide. In this direction, how Turkish children's literature can support child development and child education is examined. 


\section{Method}

This is a case study. Within the scope of the study, documents (children's book publication catalogs) were examined, information-data (theme/subject) was collected from these documents, and thematic trends of Turkish children's literature were described. This process constitutes the core of a case study (Creswell, 2016, p. 97). The present study was designed as an embedded single case study in which a single unit of analysis (themes) was divided into sub-units (sub-themes and subjects) (Yin, 2003, p. 42). Additionally, themes and subjects in Turkish children's literature were interpreted and discussed in both curricular and extra-curricular contexts. Therefore, the study has multidimensional aspects.

\section{Study Object}

The study object was chosen according to criterion sampling. In this sample, data that meet certain criteria are included in the study (Patton, 2014, p. 243). In this direction, firstly, bookselling websites were examined, and publishing houses in children's literature were determined. Next, whether the publishing houses had publication catalogs on their websites was analyzed. Then, descriptive analysis was administered on the publication catalogs determined. Accordingly, publishing houses that provided categorical information in the catalogs such as "book summary, class-age, theme-subject, author" were selected. Since theme-subject was the analysis unit of the research, book summary (to examine themessubjects contextually), class-age information (to select children's books that appeal to the secondary school level), author information (to select Turkish authors' books) were determined as a criterion.

Secondary school children are in their last childhood and adolescence period. Their concrete and abstract world in this transition period is enriching; their mental, spiritual, and social development deepens. Also, different disciplines become more visible and effective in children's education. Similarly, children's literary world in this period is expanding both in terms of content (in line with their development level) and genre (biography, magazine, novel, informative text, etc.). For these reasons, children's books in secondary school are an ideal option for a thematic review. In addition, the inclusion of "national culture, independence war, and Atatürk" themes in the research make both Turkish children's literature and the secondary school age in which cultural and national consciousness has developed an ideal sample. 
Turkish children's books ( $\mathrm{f}=665)$ meeting the criteria were included in the study. The frequencies of children's books, according to some categories, are presented below.

- Publishing House: Can Çocuk (f=190), Tudem (f=190), Günışığı Kitaplığı ( $f=154)$, Bilgi $(\mathrm{f}=131)$

- Genre: novel ( $\mathrm{f}=411$ ), story ( $\mathrm{f}=148)$, legend-epic-tale ( $\mathrm{f}=28)$, informative ( $\mathrm{f}=27)$, poem $(\mathrm{f}=18)$, anecdote-cartoon-riddle-humour $(\mathrm{f}=12)$, memory-narrative $(\mathrm{f}=7)$, biography $(\mathrm{f}=5)$, essay-literary diary-travel literature-review-graphic novel ( $\mathrm{f}=9$ )

- Grade Level: the fifth grade $(\mathrm{f}=587)$, the sixth grade $(\mathrm{f}=446)$, the seventh grade $(\mathrm{f}=248)$, the eighth grade $(\mathrm{f}=182)$

- Author's gender: eighty-eight female authors ( $f=352)$, ninety-two male authors $(f=309)$

When the above-mentioned data are examined, it can be concluded that children's books show a homogeneous distribution according to the publishing house and the author's gender. There is an imbalance in the distribution of children's books according to the genre and grade level. These distributions reflect the policy of publishing houses directly. Additionally, no comparison was made between categories (publishing house, genre, grade level, author's gender). For these reasons, a homogeneous sample selection was not applied.

\section{Data Collection Tools}

Documents were used as data collection tools in the study. Categories, according to which documents are analyzed, can be determined in accordance with the relevant literature before data analysis (Yıldırım \& Şimşek, 2013, p. 228). The categories to be used in the analysis of the data must reflect the study's purpose, display a comprehensive structure, and each subcategory must be independent of the others (Holsti, 1969, p. 95). Based on this, while forming the categories, the Turkish Lesson Curriculum was taken as an example, as it was taken as an example in the book catalogs of the publishing house. The program in question includes sixteen themes and subject proposals for these themes (MEB, 2019, pp. 15-16).

\section{Data Analysis}

Deductive content analysis was administered on the data obtained from the study object according to the sixteen themes and the subjects covered by these themes. In this technique, the collected data are analyzed according to pre-determined categories (Patton, 2014, p. 453). Units used in data analysis were words and word groups. These units of analysis were 
limited in form and had a semantically comprehensive structure. Because the word and word groups have a feature of being a subject and a theme in line with the statements of publishing houses, it significantly prevents research subjectivity and bias, which is an important problem in determining the issues and themes in the documents (Bailey, 1994, p. 308).

Data were analyzed from a smaller unit to a larger unit. These units were listed as sub-topics<topic<theme. For example, the subject of "analyzing" in the book catalog was coded as analyzing <mental development<personal development. Similarly, the "selfknowledge" subject was coded as self-knowledge<personal development. Depending on the scope of the subject, these sub/topics may vary. Since accurate coding of the topics requires special concept knowledge, firstly, thematic reference sources, and thematic dictionaries were used. In cases where these resources were insufficient, online search engines were used.

In the book catalogs, Bilgi and Tudem publishing houses provided information on the sub-theme and subject, Günışığı Kitaplığı and Can Çocuk publishing houses provided information on both theme and sub-theme and subject information. However, it was not clear which subjects were related to which themes because they were included in separate sections in the catalogs. Sometimes it is difficult to decide which category to cover unless the context in which the data (word, phrase, etc.) in the document is examined. In such a case, researchers should pay attention to context while coding the data (Bailey, 1994, p. 308). At this point, the researchers carefully examined the information (summary, activity, theme, subject) available in the catalogs about a book. In line with this examination, thematic coding was carried out as a sub-topic<topic<theme. For example, the subject of "Istanbul" primarily fell under the "time and space" theme. If there was a culture-oriented theme in children's book or if Istanbul's historical and cultural value was mentioned in the book summary, this subject was also coded to a "national culture" theme. As a different example, the subject of "life" simply did not fall within the scope of any theme. If additional information about life was not available in the theme and the book summary, this topic was excluded from the study.

Two researchers coded the data separately. After coding was completed, agreement $[$ Reliability=Agreement/(Agreement+Disagreement)] between coders was calculated (Miles \& Huberman, 1994). In this direction, the agreement was calculated as $85 \%$, showing that researchers conducted a consistent analysis process. In the next process, the researchers 
examined the incompatible coded subjects together and re-coded them. After the re-coding process was completed, an independent researcher whose expertise area was children's literature was consulted to ensure an external check. The context of the study and data analysis process was explained to this researcher, and data from 70 children's books were shared with him. According to Lombard, Snyder - Duch, and Bracken (2002), sharing at least $10 \%$ of the sample is sufficient. In line with the coding of the researcher, a coding agreement was calculated as $81 \%$, and this percentage was found to be adequate.

After the deductive qualitative data analysis was completed, quantitative content analysis (frequency/frequency) was administered on the data in two different categories (theme, subject). Accordingly, themes which the children's books covered and subjects which the themes covered were determined.

\section{Data Presentation}

After the content analysis is administered on the data, they can be presented in four different quantitative approaches: (1) presence or absence of the theme and subject; (2) frequency of the theme and subject; (3) the percentage of the theme and subject; (4) the theme and the area covered by the subject (Bailey, 1994, p. 309). However, it is not mandatory to present the data obtained through document analysis in numbers or by quantifying. The researcher has the initiative to report the data in a text form (Yıldırım \& Şimşek, 2013, p. 200). In this study, the data were presented in both qualitative and quantitative forms. However, by the nature of the qualitative paradigm and thematic study, the research data were presented as qualitatively as possible together with quantitative references (yes-no, more-less, stand outfall behind, focused-ignored, etc.).

\section{Reliability and Validity}

A valid and reliable qualitative research is required to be credible, transferable, dependable, and confirmable (Lincoln \& Guba, 2013, pp. 104-105). In line with this requirement, some strategies were used within the research (Merriam \& Tisdell, 2015, p. 259). Accordingly, data were selected by using purposeful sampling, data source and researcher triangulation were applied, the context of the research was described, the procedure of the study and findings were explained in-detail, independent researcher supervision was applied, and measures were taken for the subjectivity and against the bias of the researcher. 


\section{Findings}

Statistics based on frequency (f) and percentage (\%) of the themes identified in Turkish children's books are presented in Table 1 .

Table 1. Number of Books in which Themes were Identified

\begin{tabular}{lccccc}
\hline & $\mathrm{f}$ & $\%$ & & $\mathrm{f}$ & $\%$ \\
\hline Virtues & 505 & 76 & Citizenship & 218 & 33 \\
Individual and Society & 495 & 74 & National Culture & 173 & 26 \\
Personal Development & 469 & 71 & Art & 148 & 22 \\
Communication & 440 & 66 & Health and Sports & 105 & 16 \\
Emotions & 408 & 61 & Rights and Freedom & 103 & 15 \\
Children's World & 404 & 61 & Science and Technology & 98 & 15 \\
Time and Space & 333 & 50 & Reading Culture & 68 & 10 \\
Nature and Universe & 275 & 41 & Independence War and & 18 & 3 \\
& & & Atatürk & & 100 \\
\hline
\end{tabular}

Virtues are the most common theme in Turkish children's books. Individual and Society, Personal Development, Communication, Emotions, and Children's World themes are also available in many children's books, followed by Time and Space, Nature, and the Universe, respectively. Citizenship, National Culture, Art, Health and Sports, Rights and Freedoms, Science and Technology, Reading Culture, Independence War, and Atatürk themes are included in children's books, little or very little.

\section{Virtues}

The content of Virtues theme is as follows: friendship (22.4\%), love (18.5\%), solidarity (15.0\%), empathy (5.4\%), responsibility (3.8\%), kindness (3.4\%), respect (3.0\%), prejudice (2.8\%), fairness $(2.8 \%)$, virtue (2.7\%), courage (2.6\%), cooperation $(2.2 \%)$, ethics $(2.1 \%)$, honesty $(1.9 \%)$, peace $(1.9 \%)$, tolerance $(1.5 \%)$, altruism $(1.3 \%)$, brotherhood $(0.9 \%)$, protection $(0.9 \%)$, trust $(0.6 \%)$, sharing $(0.6 \%)$, righteousness $(0.6 \%)$, perseverancediligence (0.5\%), having a conscience (0.5\%), mercy (0.4\%), appreciation (0.3\%), loyalty $(0.2 \%)$, compromise-agreement $(0.2 \%)$, wisdom $(0.2 \%)$, commitment $(0.2 \%)$, generosity $(0.1 \%)$, benevolence $(0.1 \%)$, fidelity $(0.1 \%)$, selfishness $(0.1 \%)$, willpower $(0.1 \%)$, sensitivity $(0.1 \%)$, forgiveness $(0.1 \%)$. 
It is observed that on the one hand, emotions and influences based on character virtues dominate the theme. The virtues of thought, on the other hand, are very poorly covered. In other words, it can be concluded that the theme focuses on moral virtues and ignores the virtues of thought. In character virtues, it is observed that the virtues that strengthen interpersonal communication and relationship in a child's social life are dominant. At the same time, there are virtues centered on helping and sharing in which the other person-creature is focused. Besides, virtues that support personal development are also covered. Finally, the presence of good and bad, which is an important abstract concept in the social development of secondary school children, is remarkable.

When the theme is examined according to the root values (justice, friendship, honesty, self-control, patience, respect, love, responsibility, benevolence), which are considered to be educationally important, it is observed that the two most discussed topics (friendship and affection) are root values. In addition, responsibility, respect, justice, cooperation, and honesty issues come to the theme's fore. However, patience and selfcontrol values are not included in the theme. Considering that values/virtues supporting friendship, honesty, patience, respect, love, and benevolence, which are among the root values, are covered in the theme, theme has important educational potential.

Virtues are closely related to the moral development of a child. Secondary school children, who are in the early stages of their moral development, perceive and understand virtues better when they are embodied. Children's books are a suitable tool to convey morally ideal or controversial situations since they reflect real people, cases, relationships, in other words, to embody virtues. Accordingly, the theme has the potential to support the moral development of children. However, focusing on certain character virtues in the theme limits this potential.

\section{Individual and Society}

The content of Individual and Society theme is as follows: solidarity (21.2\%), individual and society (9.4\%), social life and relationships (8.3\%), empathy (7.9\%), professions (7.7\%), individual differences (7.0\%), civilization (6.2\%), neighbourhood relations (5.0\%), justice (4.0\%), peace (3.3\%), rural culture (3.3\%), urban culture (2.6\%), homesickness (2.5\%), social rules-laws (1.9\%), equality (1.8\%), brotherhood $(1.2 \%)$, cultural differences (1.1\%), multiculturalism (0.8\%), disadvantaged groups $(0.8 \%)$, power $(0.8 \%)$, social services and responsibility (0.8\%), socio-economic differences (0.6\%), law (0.3\%), 
O. Turhan, B. Baş, \& F. Karaca Turhan / Pamukkale University Journal of Education, 52, 31-58, 2021

hospitality $(0.3 \%)$, communal pressure $(0.3 \%)$, popular culture $(0.3 \%)$, multilingualism $(0.1 \%)$, respect for differences $(0.1 \%)$, life skills $(0.1 \%)$, sociocultural awareness $(0.1 \%)$.

There are many children's books in the Individual and Society theme, where only the theme is named, and no subject is included. It is possible to classify subjects in Individual and Society theme as virtues and values, differences and awareness, negative social facts, citizenship, rights, communication, economy, culture, place, and residentials. When the subjects are analyzed cumulatively, it is observed that the theme is addressed in a cultural context rather than a universal and intercultural context. Issues based on ethics-virtue, sociology, and communication are observed mostly in the subjects. At the same time, areas such as economy, geography, diplomacy-politics, human rights, and law support the theme.

By nature, children's literature has the potential to reflect society and an individual's relationship with society. However, Individual and Society is a broad theme that theoretically includes different disciplines. Therefore, it is necessary to provide conceptual and disciplinary diversity related to the theme in children's literature. Examined children's books partially lack this diversity. In addition, the theme mostly consists of topics such as virtues, citizenship, time and space, and communication. Many issues in cultural, social, political, and economic contexts that can only be addressed within this theme's scope are ignored. However, within the limitations mentioned, the theme can enable children to perceive individual and societal dynamics and learn the concepts in this context.

\section{Personal Development}

The content of Personal Development theme is as follows: mental development (17.8\%), dreaming/imagining (16.9\%), struggle (6.9\%), empathy (6.8\%), creativity (6.7\%), selfknowledge (6.3\%), maturation (5.5\%), artistic development (5.1\%), responsibility (4.9\%), education-learning (3.8\%), observation (2.3\%), emotional development (2.3\%), choice of profession (1.9\%), social development (1.8\%), personal development (1.8\%), self-confidence (1.4\%), decision making (0.8\%), self-expression (0.8\%), success (0.7\%), self-sacrifice $(0.7 \%)$, seeking $(0.6 \%)$, diligence $(0.5 \%)$, self-esteem $(0.5 \%)$, talent $(0.5 \%)$, positive thinking (0.4\%), competing (0.4\%), leading-leadership $(0.4 \%)$, determination $(0.4 \%)$, personality types $(0.2 \%)$, hobby and course $(0.2 \%)$, skills $(0.1 \%)$, self-criticism $(0.1 \%)$, choice $(0.1 \%)$, adapting $(0.1 \%)$, getting guidance $(0.1 \%)$.

There are various types of development in the theme of Personal Development. Mental development is at its center, followed by artistic development, emotional 
development, and social development. When all the subjects included in the theme are evaluated cumulatively, it is observed that many subjects supporting mental, artistic, emotional, and social development are included in the theme. Also, the topics in the Personal Development theme can be grouped in different ways. In this respect, the theme includes subjects based on creativity, academic and professional development, virtues and values, choice and decision, communication and human relations, ability and skill, and metacognition and self-management. It should be added that while focusing on career and literature, which is among the special subject areas, other special subject areas (health, sports, music, technology, etc.) are ignored.

When the subjects are analyzed cumulatively, it can be said that children's developmental areas are approached in a holistic way in terms of diversity in children's books. It is possible to list these development areas as mental development, self-identity development, artistic development, emotional development, social development, and professional development. Moral development, sexual development, and partly language development are ignored in the theme. The theme has significant potential due to its multidimensional view of personal development. However, focusing on certain subjects and personal development types in the theme limits this potential.

\section{Communication}

The content of Communication theme is as follows: family (35.6\%), friendship (33.0\%), communication (10.0\%), neighbourhood relations (5.2\%), intergenerational communication (4.1\%), communication with other creatures (3.6\%), mass media-communication tools (2.3\%), communication with people (2.0\%), self-expression $(1.4 \%)$, student-teacher communication (0.7\%), communication skills (0.6\%), intercultural communication $(0.6 \%)$, written communication $(0.4 \%)$, cultural communication $(0.3 \%)$, effective communication $(0.1 \%)$.

There are many children's books on the communication theme, where only the theme is named, and no subject is included. Verbal communication is observed more than nonverbal and written communication in the subjects included in the theme. Interpersonal communication dominates the theme. These persons are from the child's immediate environment. When the subjects are examined individually, it is observed that friends and family dominate the whole theme. In addition, cultural communication, communication skills, communication tools, communication with other living things are included. However, these issues do not have a significant weight. 
When analyzed in terms of contexts, it is observed that communication is mostly covered in social contexts and partially in cultural contexts. Communication does not have the elements of time (immediate or delayed feedback, etc.) and setting (formal or intimate, etc.). The communication skills, anxieties, and barriers that are mentally, emotionally, and socially linked to the development of children's speaking skills are not adequately addressed in the theme. Similarly, communication tools (telephone, computer, etc.) are covered very little. Since these tools play an important role in children's communication culture, these shortcomings are even more noticeable. In addition, the lack of communication types connected to communication tools (visual communication, information communication, printed, electronic communication, etc.) in the theme draws attention.

The communication theme is based on the social development of children predominantly. Children in the secondary school period contact their families and friends first, then with their teachers and other close relatives. The quality of communication with these people (especially family and friends) is a strong indicator of the social identity that children will develop. Therefore, the theme gains a significant potential for the social development of children. However, the mentioned shortcomings limit this potential.

\section{Emotions}

The content of Emotions theme is as follows: affection (31.2\%), emotions (12.6\%), curiosity (10.4\%), empathy (9.1\%), hope (6.7\%), respect (5.1\%), courage (4.4\%), longing (2.9\%), love (2.9\%), fear (2.1\%), loneliness $(2.1 \%)$, anxiety-stress $(1.6 \%)$, happiness $(1.6 \%)$, jealousy (1.3\%), excitement (1.0\%), sadness (0.8\%), trust $(0.8 \%)$, passion $(0.8 \%)$, farewell $(0.5 \%)$, arrogance $(0.3 \%)$, stress $(0.3 \%)$, envy $(0.3 \%)$, loyalty $(0.3 \%)$, forgiveness $(0.2 \%)$, regret $(0.2 \%)$, desperation $(0.2 \%)$, distress $(0.2 \%)$.

There are a significant number of children's books in the emotions theme, where only the theme is named, and no subject is included. The diversity of both positive and negative emotions stands out in the theme. However, positive emotions are more dominant. It is possible to classify the subjects in the theme as love/affection, joy, sadness/grief, fear, and anger. Among these categories, firstly love/affection, then joy stands out. Sadness, fear, and anger remain in the background.

Emotions based on love and joy are common emotions that affect the personality development of secondary school children. For this reason, it is a positive sign that they have a high frequency. Children in adolescence (late secondary school) experience all 
emotions more intensely and irregularly than in the previous period. Especially children in this period feel emotions based on love, sadness/grief, fear, and anger, greatly. These feelings are represented in children's books but much lower than other emotions. Empathy is an effective emotion in the emotional development of secondary school children. Therefore, it is noteworthy that this feeling is presented at a high level in children's books.

The theme can enable children to experience their own emotions and support their emotional development. However, underrepresentation of emotions with different qualities and focusing on certain emotions limit this potential.

\section{Children's World}

The content of Children's World theme is as follows: imagination (22.2\%), adventure (11.0\%), school (10.0\%), curiosity (9.1\%), mystery (7.5\%), growing up (6.6\%), extraordinary (5.7\%), humour (5.3\%), travel (3.8\%), game (3.5\%), pressure and exclusion (2.5\%), vacation (2.5\%), parental divorce-parent loss (2.3\%), exam-homework (1.6\%), children's world $(1.2 \%)$, dream (0.9\%), children's culture $(0.7 \%)$, entertainment $(0.7 \%)$, exploration (0.7\%), heroism (0.6\%), habits (0.4\%), admiration-envying (0.3\%), special days $(0.3 \%)$, digital games $(0.1 \%)$, gift $(0.1 \%)$, trip $(0.1 \%)$.

Children's World theme includes various key concepts that play an important role in children's mental, emotional, and social development. These concepts are very dominant in children's books. The theme is covered with a positive approach, yet some negative situations are also included. Additionally, the theme is heavily influenced by genres.

The theme, having a dynamic nature, focuses on having fun and exploring. The abstract concepts in the theme have the potential to enrich the imaginary-emotional world of children. The physical life of children is not covered much in the theme. Children's daily life is based on education and training. Also, activities such as games, traveling, and holidays that children enjoy are partly included. Although technological developments and the changes brought about by them are strong enough to shape and change children's culture today, this situation is not reflected in the theme. Changes in the world of children in a short period of time are revealed in terms of growth. However, the theme focuses on the early period rather than the late period of secondary school. Concepts reflecting the physiological, psychological, and social worlds of adolescent children are ignored in the theme.

Children begin or keep reading a book if they find something from their life and their own world. Secondary school children's worlds differ from one another due to periodic (late 
childhood-puberty) and individual differences (temperament, experience, socioeconomic status, etc.). Reflecting these differences in books will positively affect children's interest and desire to read books. In this context, it can be concluded that the theme is sufficient up to a certain level.

\section{Time and Space}

The content of Time and Space theme is as follows: past-present-future (24.6\%), our environment (14.5\%), our school (13.7\%), cities (11.3\%), time and place (7.5\%), countries (5.6\%), rural settlement (5.0\%), holiday and tourism (3.8\%), regions-geography (3.4\%), our house (2.0\%), camping (1.0\%), social institutions (1.0\%), historical sites $(0.8 \%)$, library (0.8\%), neighbourhood (0.6\%), zoo (0.6\%), apartment (0.4\%), museum (0.4\%), special days $(0.4 \%)$, travellers $(0.2 \%)$, our class $(0.2 \%)$, hotel $(0.2 \%)$, business $(0.2 \%)$, nursing home $(0.2 \%)$, park $(0.2 \%)$, soup kitchen $(0.2 \%)$, fire department $(0.2 \%)$, municipality $(0.2 \%)$, circus-theme park-fair (0.2\%), marketplace (0.2\%), time (0.2\%), history (0.2\%), memory $(0.2 \%)$.

There are a significant number of children's books in the Time and Space theme, where only the theme is named, and no subject is included. Although individually, the subject that is covered the most is about time, cumulatively, the subjects related to space form the focal point of the theme. There was no clear distinction between time-related issues; it is not divided into sub-segments such as past, present, and future. Time was not associated with physics, astronomy, history, archaeology, and geology. Sub-topics such as time perception, time-traveling, mythology, and science fiction that may attract children's attention are not included, either. Finally, despite being in the same theme, time and space remain independent from each other.

It is possible to classify space-related topics as small-scale and large-scale. Although the focus is on small-scale spaces, large-scale spaces are also covered significantly. Largescale spaces are limited to Turkey. Small-scale spaces are based on the child's immediate environment. It is observed that places visited for cultural, educational, and entertainment purposes are also covered in the theme. Besides, official and social institutions are included. The fact that places in the theme consist of today's familiar and real places can be interpreted both positively and negatively. Since those places are directly related to the children's daily lives, they can enable a child to associate reality with fiction better and be more motivated to read. However, places that are unknown or known very little (extraordinary, in the past or in 
the future, not in the immediate environment, etc.) are more effective in enriching the child's imagination and developing her/his imagination.

\section{Nature and the Universe}

The content of Nature and the Universe theme is as follows: animals (16.0\%), environment (15.1\%), living creatures (14.7\%), nature (14.2\%), environment protection (8.6\%), time consciousness (6.5\%), rural settlement (4.5\%), natural life (4.3\%), nature and the universe $(2.5 \%)$, seasons $(2.2 \%)$, nature events $(2.0 \%)$, earth $(1.6 \%)$, water $(1.4 \%)$, plants $(1.1 \%)$, natural disasters $(1.1 \%)$, world $(0.9 \%)$, space $(0.9 \%)$, atmosphere $(0.9 \%)$, earthworksagriculture $(0.7 \%)$, planets $(0.4 \%)$, landscapes $(0.2 \%)$, stars $(0.2 \%)$, environmental pollution $(0.2 \%)$.

In Nature and the Universe theme, issues related to the universe are ignored in terms of both diversity and frequency; instead, nature-oriented issues are focused on. Therefore, tendencies towards the sub-theme of the universe cannot be determined. However, it can be said that nature is mainly covered from a life and vitality perspective in the theme. Environmental awareness is important in pointing to ongoing climatic and environmental changes and threats globally, which is covered significantly in children's books. It is observed that subjects related to earth, water, and air, which constitute the main elements of nature, are also included in the theme. Only time consciousness is covered in the context of the time in the theme. Subjects presenting a chronological and historical perspective to nature (evolution, natural history, etc.) are not included.

Disciplines (astronomy, chemistry, earth sciences, physics, etc.) studying nature and the universe are not clearly presented in the theme. Those disciplines are conceptually not included in the theme but can be partially perceived through the subjects they are related to. Similarly, facts and phenomena on which natural and cosmological sciences are based are not clearly covered. The living and non-living elements of nature and the universe are underrepresented in terms of diversity. The theme does not touch upon studying nature and the universe by means of tools such as a telescope, microscope, camera, etc.

In terms of natural history, humans tend to be instinctively close to nature. However, despite this tendency, industry and technology's development has created a distance between man and nature. Children being away from nature physically, mentally, and emotionally because of urbanization and technology need nature in their personal development. While these needs of children can be met physically to a certain extent, certain tools (internet, 
television, book, etc.) help for more. In this theme, nature mainly consists of elements that children can physically see, hear, feel, in other words, that they can experience. In this case, the theme helps children be motivated to read and gain awareness of nature, but it does not contribute to enriching the natural world. The shortcomings mentioned throughout the theme limit its potential to develop children's natural intelligence, multiple intelligence types.

\section{Citizenship}

The content of Citizenship theme is as follows: human rights (26.5\%), freedoms $(13.1 \%)$, responsibility (10.6\%), justice (7.5\%), cooperation (7.0\%), production (5.9\%), consumption-expenditure (5.7\%), migration (4.6\%), employment (4.4\%), unemployment and financial difficulty (3.6\%), equality (3.4\%), labour (2.8\%), immigration (2.8\%), sharing $(1.5 \%)$, rule of law $(0.3 \%)$, tax awareness $(0.3 \%)$.

Human rights, basic democratic values, and social values-virtues constitute the focus of the Citizenship theme. Citizenship is also reflected in the form of economic obligations and economic difficulties. Finally, the issues of migration and immigration, being important elements of citizenship nationally and globally, are also included in children's books.

In the theme, citizenship is handled based on law and democracy, and it is also treated as an economic and a social concept. Some of the main elements of citizenship education are democracy, law, social structure, and economics. Therefore, the approach in children's books can be regarded as positive. At the same time, economic difficulties and immigration issues are valuable in showing some of the citizenship's social realities. However, it should be added that a classical-traditional approach is displayed, as citizenship is loaded with economic duties and responsibilities in the theme.

It can be concluded that constitutional and democratic citizenship is covered in the theme. However, the theme lacks many citizenship approaches (national, global, social, digital, ecological, multicultural citizenship, etc.). Accordingly, it can be stated that the theme can be a resource for citizenship education within those limitations.

\section{National Culture}

The content of National Culture theme is as follows: our values (23.7\%), cultural heritage (16.2\%), our country (16.2\%), Turkish (8.5\%), Turkish culture (8.2\%), homeland (7.7\%), traditions $(5.1 \%)$, our cities $(5.1 \%)$, historical places $(2.3 \%)$, historical artifacts $(2.1 \%)$, human relations (1.8\%), historical figures (1.3\%), holidays-religious holidays (0.5\%), 

cuisine (\% 0.3).

Values, cultural heritage, and homeland subjects are focused on in the National Culture theme. When they are examined cumulatively, it is found out that the subjects focused on moral ties, historical and cultural elements, residentials and place, and language to a great extent. Turkish culture is covered from a traditional perspective, firstly with the support of sociology, history, architecture, geography, and language, while many cultural areas such as sports, art, politics, economy, military service, folklore, cuisine, clothing, equipment are ignored.

The concept of culture represents all materials and moral elements of society, and comparison should not be made between these elements. For this reason, children need to learn the cultural elements of a society in a holistic way. Social life and interpersonal interactions are not enough for comprehending culture due to its comprehensive and deep structure. At this point, printed, visual and audio materials mediate learning. Thus, children's books gain a functional role in the cultural transfer. However, the Turkish culture elements in the theme do not show a homogeneous distribution and are not covered in a balanced way. They greatly limit the potential of the theme in the cultural transfer. However, as some important cultural areas are covered in the theme, it can be used as a cultural transfer source within the mentioned limitations.

\section{Art}

The content of Art theme is as follows: literature (38.2\%), elocution (15.7\%), art (14.7\%), music (8.9\%), artist (4.7\%), aesthetics (4.2\%), cinema/documentary/series (2.6\%), theatre (2.1\%), traditional arts (1.6\%), ombromanie (1.6\%), photography $(1.0 \%)$, painting $(1.0 \%)$, performing arts (1.0\%), festival (0.5\%), miniature (0.5\%), pantomime (0.5\%), innovative thinking (0.5\%), dance (0.5\%).

There are many children's books in the Art theme, where only the theme is named. Subjects with certain content are related to the branches of art. Subjects that indicate artistic talent, skill, sensitivity, or elements are covered at a low level in the theme. The subject of literature alone dominates the theme. Language arts' dominance stands out in the theme, followed by vocal arts, dramatic arts, visual arts, performing arts, respectively. However, other art subjects in the theme, except for the vocal arts, are hardly visible. Art subjects 
ignored in the theme can be exemplified as space arts, volumetric arts, traditional Turkish arts, new media arts, and street arts.

Children's books, being products of language and literature, represent the same art thematically. This enables children to experience literature, both theoretically and practically. However, the natural and strong bond between art subjects is not benefited by the theme's scope. Unlike life sciences and social sciences, art is an ideal field for children to meet their spiritual and affective needs and information needs. Art supports the 21st-century skills (creativity, criticism, productivity, communication), addresses different types of intelligence (musical, internal, spatial, and kinaesthetic, etc.), can be adapted to various environments (classroom, gallery, museum, workshop, exhibition, etc.) and can also be used as a functional educational tool. However, different branches of art are not included in the theme, and different aspects of art are not covered. Therefore, the theme does not offer a significant opportunity for education and artistic development through the arts.

\section{Health and Sports}

The content of Health and Sports theme is as follows: health and sports (29.8\%), illnessdisability (24.0\%), sports-sports culture (15.7\%), life and death (14.9\%), healthy life (6.6\%), physical health (2.5\%), healthy nutrition (2.5\%), nutrition (1.7\%), drug use (0.8\%), sportsmanship (0.8\%), health service $(0.8 \%)$.

There are many children's books in Health and Sports, where the theme is named a subject. Health problems dominate the health sub-theme. At the same time, issues related to body health are also covered in the theme. Sports-sports culture is covered in the sub-theme of sports.

It is possible to say that health problems stand out in the sub-theme while being healthy stays in the background. Dealing with sensitive issues such as limb deficiency, visual impairment, dyslexia, autism, down syndrome, and death is important for children to gain awareness and experience life's realities. Physical and mental health issues should be emphasized as much as health problems. However, in the theme, physical health is included less, and mental health is not addressed. Secondary school students need guidance on health as well as in many other subjects. Written texts such as brochures and handbooks are frequently used in this guidance process. Accordingly, children's books can also be used with a similar function. However, the sub-theme does not offer significant health education and guidance opportunities, as the health issue is not handled in a holistic and balanced way. 
In the modern world, modernization has reduced children's physical activities, while children's playgrounds and sports areas have decreased because of urbanization and population density. For this reason, media tools become more important for children to experience sports and gain sports culture. In this context, television channels, computer games, internet broadcasts have wider and functional use. It is also possible to use children's books. When the children's books are examined, it is observed that the sub-theme focuses on football individually, and other sports branches are not mentioned enough. In this direction, it can be said that the theme does not make use of the natural interest of children in sports properly. Being the other sub-theme, sports culture represents a holistic and complex approach (physical, mental, and emotional) to sports. For this reason, processing sports culture in the sub-theme is more important than processing pure sports branches. However, the necessary importance is not given to sports culture, either. Due to those shortcomings, it can be said that the potential of the sub-theme to expand the sports world of children and develop sports culture remains limited.

\section{Rights and Freedoms}

The content of Rights and Freedoms theme is as follows: rights and freedoms (29.8\%), freedoms-prohibitions (23.7\%), equality (10.7\%), education right (6.9\%), human rights (4.6\%), children's rights (3.8\%), freedom of religion and conscience (3.8\%), individual rights $(3.1 \%)$, belief right (3.1\%), freedom of thought (1.5\%), animal rights (1.5\%), mercy $(1.5 \%)$, injustice $(1.5 \%)$, democracy $(0.8 \%)$, freedom of speech $(0.8 \%)$, right of privacy $(0.8 \%)$, fundamental rights and freedoms $(0.8 \%)$, gender equality $(0.8 \%)$, respect for rights $(0.8 \%)$.

A large part of the Rights and Freedoms theme consists of comprehensive subjects to be a theme, yet their content is ambiguous. Other subjects appear to be included in a small number of children's books. When these issues are evaluated cumulatively, it is observed that first-generation rights consisting of personal and political rights constitute the focal point. Second-generation rights consisting of economic and social rights remain in the background in children's books. Third-generation rights, consisting of the rights of the people and solidarity, are not included. Children's rights and animal rights are covered very little.

While people's rights and freedoms are covered in the theme, the rights and freedoms of other living creatures are ignored. The ambiguous content of the subjects, which constitute a large part of the theme, prevents determining the theme's trends. When the 
subjects with open content are examined, it is observed that personal and political concepts stand out, while social, economic, and collective concepts remain in the background. Personal and political rights and freedoms covered in the theme lack many sub-topics. These shortcomings limit the potential of the theme. Due to these shortcomings, the theme's potential to enable children to learn about the rights and freedoms they have now and will have in the future, to realize that other people and other living things have rights and freedoms, thus to become conscious citizens is quite limited.

\section{Science and Technology}

The content of Science and Technology theme is as follows: science and technology (24.1\%), discovery and inventions (12.1\%), media-social media (9.2\%), communication (8.5\%), science (8.5\%), technology (7.8\%), science literacy (6.4\%), social sciences (4.3\%), internet (2.8\%), ethics (2.1\%), communication (2.1\%), imagination (2.1\%), curiosity $(2.1 \%)$, fact $(2.1 \%)$, transportation $(2.1 \%)$, phenomenon $(1.4 \%)$, scientists $(0.7 \%)$, innovation $(0.7 \%)$, computer game $(0.7 \%)$.

There are many children's books in Science and Technology theme where the theme is named as a subject. Technological developments seem to dominate the theme. In addition, the areas affected by these technological developments are also included. In the sub-theme of science, subjects related to life sciences (mathematics, biology, etc.) are covered more, and subjects related to social sciences (archaeology, history, etc.) are covered less. In addition, facts, phenomena, and scientists are partly covered in relation to the life sciences. Finally, it is observed that the concepts in which science and technology are examined and the skills required for the development of science and technology are partially included.

The theme covers concepts that illuminate various aspects of science and technology. However, significant differences between these concepts' frequency show that concept diversity is not reflected in children's books. Accordingly, it can be concluded that children are reduced to being technology (mostly computer, internet) users and consumers in the theme because the theme covers very little of science/technology competencies and skills, science/technology, and mathematics literacy. At the same time, digital competencies that directly affect the education process of children are never processed. In addition, issues in the context of science and technology production are ignored.

There is no clear trend in terms of science disciplines in the theme. They are mostly presented by name. Secondary school students' interest in science manifests itself in their 
professional choices (engineer, doctor, scientist, etc.). Establishing a relationship between science branches and career trends contributes to children's professional development and motivates them to read. However, this opportunity is not taken in the theme. Basic scientific skills and the history of science are not covered in the theme, either. In line with those shortcomings, it can be argued that the theme does not provide an opportunity to learn about the scientific process and to gain scientific knowledge and awareness.

\section{Reading Culture}

The content of Reading Culture theme is as follows: reading culture (33.6\%), reading (33.6\%), literary figures (6.9\%), reading as a passion (6.9\%), books (4.6\%), reading as an adventure (4.6\%), libraries (3.8\%), reading habits (3.8\%), bookstore (1.5\%), information literacy $(0.8 \%)$.

There are many children's books in the Reading Culture theme, where the theme's name is given as a subject. This situation further limits the theme covered in very limited children's books. Mental, psychological, and physical elements of reading are included in the subjects with clear content. However, the lack of literacy types, text formats, and reading purpose stand out in the theme. Like any cultural element, reading culture includes much more than the mental and psychological world of an individual. However, the theme does not reveal the interpersonal and social aspects of reading culture. Since the theme is not processed in a multidimensional and holistic way, the theme's potential to develop children's reading culture remains quite limited in many aspects.

\section{Independence War and Atatürk}

The content of Independence War and Atatürk theme is as follows: Atatürk (36.4\%), Republic (18.2\%), Independence War (15.2\%), national identity (12.1\%), patriotism (12.1\%), courage (3.0\%), heroism (3.0\%).

It is observed that Atatürk (in the context of education, affection, personality characteristics) dominates the Independence War and Atatürk theme. It is found out that the War of Independence, national feelings, and national identity are also handled along with the republic in the theme.

Findings reveal that the theme does not allow Atatürk to be recognized from a personal and social perspective and understand his role and importance in the Independence War and the republican period. Similarly, the theme does not have the potential to present 
information on which fronts, under which circumstances and opportunities, and based on which social values the Independence War is fought.

\section{Result}

Turkish children's literature has positive and negative thematic features in child development, child education, and diversity. Hence, it would not be correct to make a definite judgment on Turkish children's literature's thematic competence.

Themes such as virtues, individual and society, personal development, communication, emotions, and children's world, which have a wide scope and conceptual network in theory, are covered in children's books more. However, themes such as rights and freedoms, health and sports, science and technology, art, reading culture, Independence War, and Atatürk, which have a more limited scope and conceptual network since they consist of special subject areas, are mentioned at a lower level. These results are similar to previous studies conducted on a comprehensive sample (Arslantaş, 2003; Aydın, 2019; Baş, 2011). At this point, it can be stated that themes in Turkish children's literature are covered in line with their theoretical capacities, similar subjects are included in them, and no extra effort is made to cover special subject areas.

Themes (virtues, personal development, communication, emotions, etc.) which are covered in children's books more than the others, have the potential to support child development. However, it is also observed that other themes (arts, health, and sports, science and technology, rights and freedoms, reading culture, etc.) do not have the potential to support child development or have very limited potential in doing so. Usually, a single development area is covered in themes. In personal growth and children's world themes, development areas are handled more holistically. When the themes are evaluated cumulatively, it is observed that social, mental, emotional, and moral development stand out. However, it is a very big and important problem that a special development area is processed around some subjects, with a one-dimensional narrow perspective, mostly. When children's books are evaluated according to an interdisciplinary approach, it is found out that the themes lack diversity. These books offer appropriate content for some verbal lessons (human rights, citizenship and democracy, guidance and career planning, law, and justice, etc.), especially in Turkish and social studies. However, it is very limited to use them for numerical (science, mathematics, information technologies, and software, technology and design, etc.), artistic (music, visual arts, etc.), and physical (physical education and games, etc.) courses. On one hand, children's books can develop communicative, social, and 
citizenship-based competencies. On the other hand, its potential to support competencies built on mathematics, science, technology, initiative-taking, entrepreneurship, cultural awareness, learning to learn is limited. In addition, the prominence of root values (justice, friendship, honesty, respect, love, responsibility) in themes increases the educational quality of children's books. Finally, it is observed that some extracurricular gains are aimed in terms of child education in books. Among these, the child's being a person with moral values, developing himself in various ways, preparing himself for social life stand out.

Many topics (family, friends, emotions, dreams, animals, creatures, school, environment, growing up-maturing, etc.) that appeal to children in general and that are related to their experiences are intensely covered in children's books. However, special subject areas (science, technology, hobbies, sports, fashion, art, history, countries, different cultures, celebrities, etc.) are neglected in the themes and are an important disadvantage for thematic diversity and for students with special interests. Besides, many text-based themes (curiosity, mystery, humor, adventure, miracles, etc.) that attract children's attention are covered in children's books. However, some themes belonging to this field (horror, thriller, science fiction, survival, romance, etc.) are ignored. Finally, in the themes, the harsh realities of life, negative situations to be dealt with, difficult and bad experiences (death, separation, unhappiness, loneliness, bad habits, physical and verbal violence, family and peer pressure, anxiety, mental problems, pangs of love, failure, etc.) are covered at a low level. A protective attitude towards children is displayed.

Ethical Approval: Since this study did not require scale and questionnaire application, permission from the ethics committee was not required.

Conflict Interest: The authors declare no conflict of interest.

Authors Contributions: The authors have contributed equally to this paper. 


\section{References}

Akbayır, S., \& Şahin, Ş. (2005). Yaş gruplarına göre çocuklar için edebiyat. Hece. 104-105, 190-204.

Anderson, N. A. (2006). Elementary children's literature: The basics for teachers and parents. Boston, MA: Pearson.

Appel, M., \& Richter, T. (2007). Persuasive effects of fictional narratives increase over time. Media Psychology, 10(1), 113-134.

Arslantaş, H. (2003). Cumhuriyet sonrası (1981-2001) çocuk romanlarında tema, dil ve eğitim öğeleri. Yayımlanmamış yüksek lisans tezi, Dokuz Eylül Üniversitesi Eğitim Bilimleri Enstitüsü, İzmir.

Aydın, E. (2019). Türk edebiyatındaki ödüllü çocuk romanlarında temalar (1948-2016). Yayımlanmamış doktora tezi, Sakarya Üniversitesi Eğitim Bilimleri Enstitüsü, Sakarya.

Bailey, K. (1994). Methods of social research. New York: The Free Press.

Barone, D. M. (2010). Children's literature in the classroom: Engaging lifelong readers. New York, NY: Guilford Press.

Baş, B. (2011). İlköğretim yüz temel eserin Türkçe dersi öğretim programındaki temalar açısından analizi. Mustafa Kemal Üniversitesi Sosyal Bilimler Enstitüsü Dergisi, $8(15), 175-200$.

Bee, H., \& Boyd, D. (2009). Çocuk gelişim psikolojisi. İstanbul: Kaknüs Yayıncılık.

Berger, K. S. (2000). The developing person through childhood and adolescence. New York: Worth Publishers.

Bucher, K. T., \& Hinton, K. (2014). Young adult literature: Exploration, evaluation, and appreciation. Upper Saddle River, NJ: Prentice Hall.

Camp, D. (2007). Who's reading and why: Reading habits of 1 grade through graduate students. Reading Horizons Journal, 47(3), 251-258.

Creswell, J. W. (2016). Nitel araştırma yöntemleri: Beş yaklaşıma göre nitel araştırma ve araştırma deseni. Ankara: Siyasal Kitabevi. 
Darigan, D., Tunnell, M., \& Jacobs, J. (2002). Children's literature: Engaging teachers and children in good books. Upper Saddle River, NJ: Prentice Hall.

Davila, D., \& Patrick, L. (2010). Asking the experts: What children have to say about their reading preferences. Language Arts, 87(3), 199.

Davis, J. C., \& Palmer, J. (1992). A strategy for using children's literature to extend the social studies curriculum. Social Studies, 83(3), 125-128

Doğan, Y. (2007). İlköğretim çağındaki 10-14 yaş grubu öğrencilerinin gelişim özellikleri. Uludağ Üniversitesi Fen-Edebiyat Fakültesi Sosyal Bilimler Dergisi, 8(13), 155-187.

Estes, T. H., \& Vasquez-Levy, D. (2001). Literature as a source of information and values. Phi Delta Kappan, 82(7), 507-512.

Galda, L., \& Cullinan, B. (2002). Literature and the child. Belmont, CA: Wadsworth.

Gander, M. J., \& Gardiner, H. W. (2004). Çocuk ve ergen gelişimi. Ankara: İmge Kitabevi Yayınları.

Halverson, D. (2011). Writing young adult fiction for dummies. Indiana: Wiley Publishing

Holsti, O. R. (1969). Content analysis for the social sciences and humanities. Reading, MA: Addison-Wesley.

Hopkins, E., \& Weisberg, D. S. (2017). The youngest readers' dilemma: A review of children's learning from fictional sources. Developmental Review, 43, 48-70.

Horning, K. T. (1997). From cover to cover: Evaluating and reviewing children's books. New York: HarperCollins.

Huck, C. S., Hepler, S., \& Hickman, J. (1987). Children's literature in the elementary school. NY: Holt, Rinehart and Winston.

Ivey, G., \& Johnston, P. H. (2013). Engagement with young adult literature: Outcomes and processes. Reading Research Quarterly, 48(3), 255-275.

Kim, J. Y., \& Anderson, T. (2011). Reading across the curriculum: A framework for improving the reading abilities and habits of college students. Journal of College Literacy \& Learning, 37, 29-40.

Krashen, S. (2005). Free voluntary reading: New research, applications, and controversies. In G. Poediosoedarmo (Eds.), Innovative approaches to reading \& writing 
instruction, anthology series 46(pp. 1-9). Republic of Singapore: SEAMEO Regional Language Centre.

Krashen, S. (2006). Free reading: Is it the only way to make kids more literate?. School Library Journal, 52(9), 42-45.

Lincoln, Y. S., \& Guba, E. G. (2013). The constructivist credo. New York, NY: Left Coast Press.

Lombard, M., Snyder-Duch, J., \& Bracken, C. C. (2002). Content analysis in mass communication: Assessment and reporting of intercoder reliability. Human Communication Research, 28(4), 587-604.

Lynch-Brown, C. G., Tomlinson, C. M., \& Short, K. G. (2010). Essentials of children's literature. New York: Pearson.

McClure, A. A., Garthwait, A. \& Kristo, J. V. (2015). Teaching children's literature in an era of standards. Boston: Pearson.

Merriam, S. B., \& Tisdell, E. J. (2015). Qualitative research: A guide to design and implementation. San Francisco: Jossey-Bass.

Miles, M. B., \& Huberman, A. M. (1994). An expanded sourcebook qualitative data analysis. California: Sage Pablication.

Millî Eğitim Bakanlığı (MEB). (2019). Türkçe Dersi Öğretim Programı (İlkokul ve Ortaokul 1-8. Sinıflar). Ankara: Millî Eğitim Bakanlığı Yayınları.

Morgan, D. N., \& Wagner, C. W. (2013). What's the catch?: Providing reading choice in a high school classroom. Journal of Adolescent \& Adult Literacy, 56(8), 659-667.

Nuba, H., Sheiman, D., \& Searson, M. (2016). Children's literature: Developing good readers. London: Routledge.

Pantaleo, S. (2002). Children's literature across curriculum: An Ontario Survey. Canadian Journal of Education, 27(2\&3), 211-230.

Patton, M. Q. (2014). Nitel araştırma ve değerlendirme yöntemleri. Ankara: Pegem Yayıncilık.

Ross, E. P. (1994). Using children's literature across the curriculum. Fastback 373. Bloomington, IN: Phi Delta Kappa. 
Samuels, B. G. (1989). Young adults' choices: Why do students" really like" particular books?. Journal of Reading, 32(8), 714-719.

Sawyer, W. (2000). Growing up with literature. Albany, NY: Delmar.

Schanzer, R. (1996). Evaluating and selecting literature for children. Boston: Houghton Mifflin Company.

Smith, C. B. (1991). Using literature across the curriculum. Reading Teacher, 44(7), 516.

Tomlinson, C. M., \& Lynch-Brown, C. (2007). Essentials of young adult literature. Boston: Pearson.

Tunnell, M. O., \& Jacobs, J. S. (2007). Children's literature, briefly. Upper Saddle River, NJ: Pearson.

Wilhelm, J. (2015). Let them read trash!. English in Aotearoa, 85, 16-22.

Wolf, S. (2004). Interpreting literature with children. Mahwah, NJ: Lawrence Erlbaum.

Yıldırım, A., \& Şimşek, H. (2013). Sosyal bilimlerde nitel araştırma yöntemleri. Ankara: Seçkin Yayıncılık.

Yin, R. K. (2003). Case study research: Design and method. Thousand Oaks, London, New Delhi: SAGE Publications. 